九州大学学術情報リポジトリ

Kyushu University Institutional Repository

Reverse phenomena of magnetic field effects and time-resolved EPR spectra in the photogenerated biradical from intramolecular electron-transfer in a phenothiazine-C_ $\langle 60\rangle$ linked compound with a semi-rigid spacer

Moribe, Shinya

Department of Materials Physics and Chemistry, Graduate School of Engineering, Kyushu University

Yonemura, Hiroaki

Department of Applied Chemistry, Faculty of Engineering, Kyushu University

Wakita, Yuya

Department of Materials Physics and Chemistry, Graduate School of Engineering, Kyushu University

Yamashita, Tetsuya

Department of Materials Physics and Chemistry, Graduate School of Engineering, Kyushu University

他

http://hdl. handle. net/2324/26027

出版情報：Molecular Physics. 108 (15)，pp.1929-1940，2010-10-10. Taylor \& Francis バージョン：

権利関係 : (C) 2010 Taylor \& Francis 


\title{
Reverse phenomena of magnetic field effects and time-resolved EPR spectra in the photogenerated biradical from intramolecular electron-transfer in a phenothiazine- $\mathrm{C}_{60}$ linked compound with a semi-rigid spacer
}

\author{
Shinya Moribe ${ }^{1}$, Hiroaki Yonemura $^{2}$, Yuya Wakita $^{1}$, Tetsuya \\ Yamashita $^{1}$, and Sunao Yamada ${ }^{2}$ \\ ${ }^{1}$ Department of Materials Physics and Chemistry, Graduate School of Engineering, \\ Kyushu University, 744 Motooka, Nishi-ku, Fukuoka 819-0395, Japan \\ ${ }^{2}$ Department of Applied Chemistry, Faculty of Engineering, Kyushu University, 744 \\ Motooka, Nishi-ku, Fukuoka 812-8581, Japan
}

*Corresponding Author E-mail: yonemura@mail.cstm.kyushu-u.ac.jp

\begin{abstract}
Photoinduced electron-transfer reactions and magnetic field effects (MFEs) on the decay rates of the photogenerated biradical in a phenothiazine $(\mathrm{Ph})-\mathrm{C}_{60}$ linked compound with a biphenyl group $\left(\mathrm{Ph}(\mathrm{BP}) \mathrm{C}_{60}\right)$ were examined in benzonitrile and benzene. Fluorescence and transient absorption spectra indicate that the intramolecular electron-transfer for $\mathrm{Ph}(\mathrm{BP}) \mathrm{C}_{60}$ from the $\mathrm{Ph}$ to the singlet or triplet excited state of $\mathrm{C}_{60}$ was suppressed by the biphenyl group. The decay rates of the photogenerated biradical decreased in the $0-0.2 \mathrm{~T}$ magnetic field range and increased in the $0.2-1 \mathrm{~T}$ magnetic field range. The reverse phenomena of the MFEs in $\mathrm{Ph}(\mathrm{BP}) \mathrm{C}_{60}$ were strongly enhanced with increasing temperature and similar to those in $\mathrm{Ph}(\mathrm{n}) \mathrm{C}_{60}(\mathrm{n}=6-12)$. The MFEs in $\mathrm{Ph}(\mathrm{BP}) \mathrm{C}_{60}$ can be governed by spin-lattice relaxation and/or spin-spin relaxation mechanisms as observed in $\mathrm{Ph}(\mathrm{n}) \mathrm{C}_{60}(\mathrm{n}=6-12)$. Time-resolved EPR spectra of $\mathrm{Ph}(\mathrm{BP}) \mathrm{C}_{60}$ showed absorption, emission, absorption and emission patterns, and are quite different from those in $\mathrm{Ph}(\mathrm{n}) \mathrm{C}_{60}(\mathrm{n}=4-12)$. The result indicates that the magnitude and distribution of the exchange interaction $|2 \mathrm{~J}|$ in $\mathrm{Ph}(\mathrm{BP}) \mathrm{C}_{60}$ are smaller than those in $\mathrm{Ph}(\mathrm{n}) \mathrm{C}_{60}(\mathrm{n}=4-12)$ and charge recombination occurs in the inverted region because the sign of the $\mathrm{J}$ is positive.
\end{abstract}

Keywords: magnetic field effect; biradical; time-resolved EPR; phenothiazine; $\mathrm{C}_{60}$

\section{Introduction}

There has been considerable interest in photoinduced electron-transfer reactions in donor (D)- $\mathrm{C}_{60}$ systems [1-3]. $\mathrm{C}_{60}$ has been used in solar energy conversion systems such as dye-sensitized solar cells [4] and organic thin-film solar cells [5]. For further applications, a deeper understanding of the photoinduced electron-transfer reactions using $\mathrm{C}_{60}$ is required. However, few studies have focused on the spin chemistry in photoinduced electron-transfer reactions in $\mathrm{D}-\mathrm{C}_{60}$ systems. 
Magnetic field effects (MFEs) on the reaction kinetics and yields of photochemical reactions in the condensed phase have been studied [6-8]. The MFEs have been powerful for verifying the mechanism in photochemical reactions. We have examined photoinduced electron-transfer reactions and MFEs on the photogenerated biradicals in phenothiazine $(\mathrm{Ph})-\mathrm{C}_{60}$ and zinc-tetraphenylporphyrin $(\mathrm{ZnP})-\mathrm{C}_{60}$ linked compounds with different methylene groups $\left(-\left(\mathrm{CH}_{2}\right)_{\mathrm{n}}-\right)\left(\mathbf{P h}(\mathbf{n}) \mathbf{C}_{\mathbf{6 0}}(\mathbf{n}=\mathbf{4}, \mathbf{6}, \mathbf{8}, \mathbf{1 0}\right.$, 12) $[9-14]$ and $\left.\mathbf{Z n P}(\mathbf{n}) \mathbf{C}_{60}(\mathbf{n}=\mathbf{4}, \mathbf{8})\right)[15,16]$ (Scheme 1) and a rutheniumtetraphenylporphyrin- $\mathrm{C}_{60}$ ligand complex [17]. In both D- $\mathrm{C}_{60}$ linked compounds, the decay rate constant $\left(\mathrm{k}_{\mathrm{d}}\right)$ of the photogenerated biradical decreased in lower magnetic fields, yet this constant increased in higher magnetic fields, and that a reverse phenomena in the MFEs were clearly found around $0.1-0.2 \mathrm{~T}$. In addition, the temperature dependence of the reverse phenomena in the MFEs strongly indicated that the MFEs are interpreted in terms of spin relaxation mechanisms. The reverse phenomenon of the MFEs in D-acceptor (A) linked compounds can be explained by the spin-lattice relaxation (SLR) mechanism due to the anisotropic Zeeman $(\delta g)$ interaction [18]. However, the reverse phenomena of the MFEs in D-C 60 linked systems cannot be explained by only the SLR mechanism caused by the $\delta \mathrm{g}$ interaction, which depends on the local motion of each radical in the biradical. This is because the anisotropy of the $\mathrm{C}_{60}$ anion radical is very small [19]. The effect of the methylene chain length on the reverse phenomena of MFEs in $\mathbf{P h}(\mathbf{n}) \mathbf{C}_{60}$ and $\mathbf{Z n P}(\mathbf{n}) \mathbf{C}_{60}$ indicated that the reverse phenomena of the MFEs may be explained by the contribution of not only the SLR mechanism but also the spin-spin relaxation (SSR) mechanism related to the electron exchange interaction $(|2 \mathrm{~J}|)$ between two radicals in the biradical $[14,16]$. However, little is known about the reverse phenomena of the MFEs caused by the contribution of the SSR mechanism due to the $\delta \mathrm{g}$ interaction, 
except for those in $\mathrm{D}_{-} \mathrm{C}_{60}$ linked compounds with flexible methylene groups $\left(\mathbf{P h}(n) \mathbf{C}_{60}\left(\mathbf{n}=\right.\right.$ 4-12) $\mathbf{Z n P}(n) \mathbf{C}_{60}(\mathbf{n}=4,8)$, and $\left.\mathbf{Z n P}(n) \mathbf{V}(\mathbf{n}=4)\right)[14,16,20]$.

Molecular motion of a biradical bound at both ends of a flexible methylene chain has various types such as open-closed motion [21] and the local motion of each radical moiety, leading to $\mathrm{J}$ modulation [22]. Open-closed motion gives an open form and a closed form [21]. In the open form, the $\mathrm{J}$ and spin-orbit interaction of the two radicals are expected to become quite small. Conversely, in the closed form, these interactions have appreciative values. However, the influence of the motion of the spacer in the biradical on the reverse phenomena of the MFEs has not been investigated.

In the present paper, we examined the MFEs on the decay rates and timeresolved EPR (TREPR) of a photogenerated biradical in a $\mathrm{Ph}-\mathrm{C}_{60}$ linked compound with a semi-rigid bridge, which consists of a biphenyl group (Ph(BP) $\left.\mathbf{C}_{\mathbf{6 0}}\right)$ (Scheme 1). The biphenyl spacer can suppress the open-closed motion in the photogenerated biradical and consequently the closed form can be ignored. We discuss the influence of the spacer motion in the photogenerated biradicals on the reverse phenomena of the MFEs and the TREPR in $\mathrm{Ph}-\mathrm{C}_{60}$ linked compounds by a comparison between $\operatorname{Ph}(\mathbf{n}) \mathbf{C}_{60}$ and $\mathbf{P h}(\mathbf{B P}) \mathbf{C}_{60}$.

\section{Experimental}

$\mathrm{Ph}-\mathrm{C}_{60}$ linked compounds with flexible methylene groups $\left(\mathbf{P h}(\mathbf{n}) \mathbf{C}_{\mathbf{6 0}}(\mathbf{n}=4-\right.$ 12)) and a reference $C_{60}$ compound $\left(\mathbf{C}_{60}\right.$ ref) (Scheme 1) were synthesized according to previous work $[9,10,14]$. The procedure for the synthesis of the phenothiazine- $\mathrm{C}_{60}$ linked compound with a biphenyl group $\left(\mathbf{P h}(\mathbf{B P}) \mathbf{C}_{\mathbf{6 0}}\right)($ Scheme 1) is shown in Scheme 2. The synthesis of $\mathbf{P h}(\mathbf{B P}) \mathbf{C}_{\mathbf{6 0}}$ was performed as follow. 10-\{4-(4'-bromomethyl)biphenylmethyl phenothiazine (1) was prepared from phenothiazine and 4,4'- 
bis(bromomethyl)biphenyl. The crude product was purified by column chromatography (Si gel/n-hexane). 10-[4-\{4'-(p-formylphenoxy-methyl)biphenylmethyl\}] phenothiazine (2) was prepared from (1). A solution of 1,4hydroxybenzaldehyde and $\mathrm{K}_{2} \mathrm{CO}_{3}$ in dry DMF was stirred at $90{ }^{\circ} \mathrm{C}$ for 20 hours. The crude product was purified by column chromatography $\left(\mathrm{Si}\right.$ gel/ $\left.\mathrm{CHCl}_{3}\right)$. The final product $\left(\mathbf{P h}(\mathbf{B P}) \mathbf{C}_{\mathbf{6 0}}\right)$ was synthesized by 1,3-dipolar cycloaddition of the foregoing phenothiazine derivative (2), N-methylglycine and $\mathrm{C}_{60}$. The product was purified by column chromatography (Si gel/toluene and n-hexane) and recrystallized. The purity of the product was confirmed by ${ }^{1} \mathrm{H}-\mathrm{NMR}$ and MALDI-TOF mass spectra $(\mathrm{Mw}=$ 742.67). Benzene (Dojindo, spectrosol) and benzonitrile (Tokyo Kasei, guaranteed regent) were used as received. All other chemicals (reagent grade) were purchased commercially.

Steady-state absorption spectra were recorded on a Shimadzu UV-2500PC or UV-3150 spectrometer. Steady-state fluorescence spectra were measured on a JASCO FP6500 spectrometer. Cyclic voltammetry (CV) and differential pulse voltammetry (DPV) were carried out on a BAS CV-50W instrument using a three-electrode cell equipped with platinum working and counter electrodes, and an $\mathrm{Ag}$ wire as a reference electrode. The redox peak of ferrocenium/ferrocene $\left(\mathrm{Fc}^{\circ+} / \mathrm{Fc}\right)$ was used as an external standard. In each case, the solution containing a sample $\left(0.1-1 \mathrm{mmol} \mathrm{dm}^{-3}\right)$ and $\mathrm{n}-\mathrm{Bu}_{4} \mathrm{NClO}_{4}\left(0.1 \mathrm{~mol} \mathrm{dm}{ }^{-3}\right)$ as a supporting electrolyte was deaerated by bubbling with $\mathrm{N}_{2}$ before measurements.

For laser photolysis experiments, a solution of $\mathbf{P h}(\mathbf{B P}) \mathbf{C}_{\mathbf{6 0}}\left(0.1 \mathrm{mmol} \mathrm{dm}{ }^{-3}\right)$ in a cylindrical quartz cell $(3.5 \mathrm{~cm}$ optical path length) with a water jacket was deoxygenated by repeated freeze-pump-thaw cycles. The cell was placed in the gap of an electromagnet and was irradiated by a $532 \mathrm{~nm}$ laser light (Continuum Surelite I 
Nd-YAG, pulse width 4-6 ns; $10 \mathrm{~mJ})$. The transient signals from a photomultiplier (R928 Hamamatsu Photonics Co., Ltd.) with a wide-band preamplifier (NF Electronic Instruments BX-31) were recorded by a digital storage oscilloscope (Tektronix TDS350P). The signals were analyzed by a microcomputer [14].

The sample solution was prepared by dissolving $\mathbf{P h}(\mathbf{B P}) \mathbf{C}_{60}$ in benzene or benzonitrile $\left(0.1-0.3 \mathrm{mmol} \mathrm{dm}{ }^{-3}\right)$. The time-resolved EPR spectra were measured by the standard method using a quartz cell ( $5 \mathrm{~mm}$ in o.d.) or a flow method using a flat quartz cell $(0.3 \mathrm{~mm}$ light path) at room temperature $[14,16]$. The sample cell was fixed in a cavity of the EPR spectrometer (JEOL RE3X) with a quartz window and was irradiated by a Nd-YAG laser (Continuum Surelite I; $532 \mathrm{~nm}$, pulse width 4-6 ns; $10 \mathrm{~mJ}$ ) through the quartz window. Transient EPR signals were obtained by the direct method without field modulation and were recorded by a digitizing oscilloscope (Nicolet 450). The signals for the range of the investigation of the magnetic fields were assembled by a microcomputer to obtain the time-resolved EPR spectra.

\section{Results and Discussion}

\subsection{Characterisation of $P h(B P) C_{60}$}

Absorption spectra of $\mathbf{P h}(\mathbf{B P}) \mathbf{C}_{60}$ and $\mathbf{C}_{60}$ ref in benzonitrile and benzene were measured. In benzonitrile, the observed spectra of $\mathbf{P h}(\mathbf{B P}) \mathbf{C}_{60}$ and $\mathbf{C}_{60}$ ref agreed well in the wavelength range of $400-800 \mathrm{~nm}$. A Ph moiety has no absorption band above $400 \mathrm{~nm}$. Similar results were obtained in benzene. It is suggested that there are no electronic interactions between $\mathrm{Ph}$ and $\mathrm{C}_{60}$ moieties in the linked compound in both solvents, as previously reported for $\operatorname{Ph}(\mathbf{n}) \mathbf{C}_{60}(\mathbf{n}=\mathbf{4 - 1 2})$ with flexible methylene spacers [9-14]. 
Fluorescence spectra of $\mathbf{P h}(\mathbf{B P}) \mathbf{C}_{60}, \mathbf{P h}(\mathbf{1 0}) \mathbf{C}_{60}, \mathbf{P h}(4) \mathbf{C}_{60}$ and $\mathbf{C}_{60}$ ref were measured by $432 \mathrm{~nm}$ excitation in benzonitrile at $283 \mathrm{~K}$. The fluorescence band in the $700-800 \mathrm{~nm}$ range was obtained and the peak of fluorescence was observed at 717 nm for $\mathbf{P h}(\mathbf{B P}) \mathbf{C}_{60}, \mathbf{P h}(\mathbf{1 0}) \mathbf{C}_{60}, \mathbf{P h}(4) \mathbf{C}_{60}$ and $\mathbf{C}_{60}$ ref. The fluorescence intensities of $\mathrm{Ph}-\mathrm{C}_{60}$ linked compounds $\left(\mathbf{P h}(\mathbf{B P}) \mathbf{C}_{60}, \mathbf{P h}(\mathbf{1 0}) \mathbf{C}_{60}\right.$ and $\left.\mathbf{P h}(\mathbf{4}) \mathbf{C}_{60}\right)$ were smaller than the reference compound $\left(\mathbf{C}_{60}\right.$ ref). Relative fluorescence intensities of the $\mathrm{C}_{60}$ moiety of $\mathrm{Ph}-\mathrm{C}_{60}$ linked compounds, as compared with that of $\mathbf{C}_{60}$ ref, are summarized in Table 1. Table 1 indicates that the singlet excited state of $\mathrm{C}_{60}\left({ }^{1} \mathrm{C}_{60} *\right)$ was quenched by $\mathrm{Ph}$ in benzonitrile. The quenching is mainly ascribed to the photoinduced intramolecular electron-transfer reaction from $\mathrm{Ph}$ to ${ }^{1} \mathrm{C}_{60}{ }^{*}$. These results are in reasonable agreement with those in $\mathbf{P h}(\mathbf{n}) \mathbf{C}_{\mathbf{6 0}}(\mathbf{n}=\mathbf{8}, \mathbf{1 0}, \mathbf{1 2})[8-10]$. Here, the centreto-centre distances between the $\mathrm{Ph}$ and $\mathrm{C}_{60}$ moieties for $\mathbf{P h}(\mathbf{B P}) \mathbf{C}_{60} \mathbf{P h}(\mathbf{1 0}) \mathbf{C}_{60}$ and $\mathbf{P h}(4) \mathbf{C}_{60}$ were estimated to be $21.5,21.8$ and $15.4 \AA$ by assuming the conformation based on RM1 analysis. The relative fluorescence intensity for $\mathbf{P h}(\mathbf{B P}) \mathbf{C}_{60}$ was larger than that for $\mathbf{P h}(\mathbf{1 0}) \mathbf{C}_{60}$, although the distance between the $\mathrm{Ph}$ and $\mathrm{C}_{60}$ moieties for $\mathbf{P h}(\mathbf{B P}) \mathbf{C}_{60}$ was slightly shorter than for $\mathbf{P h}(\mathbf{1 0}) \mathbf{C}_{60}$. The results indicate that the quenching for $\mathbf{P h}(\mathbf{B P}) \mathbf{C}_{60}$ was suppressed by the biphenyl group acting as a semirigid bridge when compared with $\mathbf{P h}(\mathbf{1 0}) \mathbf{C}_{\mathbf{6 0}}$. This is because the more rigid biphenyl spacer suppresses the open-closed motion, which is not the case for the flexible methylene chain. By contrast, the fluorescence intensity of $\mathbf{P h}(\mathbf{B P}) \mathbf{C}_{60}$ was close to that of $\mathbf{C}_{60}$ ref in benzene. The result indicates no intramolecular electron-transfer from $\mathrm{Ph}$ to ${ }^{1} \mathrm{C}_{60} *$ takes place in benzene $[10,11]$.

Redox potentials of $\mathbf{P h}(\mathbf{B P}) \mathbf{C}_{60}$ were measured by $\mathrm{CV}$ and/or DPV in benzonitrile. Two redox couples were observed for $\mathbf{P h}(\mathbf{B P}) \mathbf{C}_{60}\left(\mathrm{E}_{1 / 2}\left(\mathrm{Ph}^{\bullet+} / \mathrm{Ph}\right)=+0.32\right.$ $\mathrm{V}$ and $\mathrm{E}_{1 / 2}\left(\mathrm{C}_{60} / \mathrm{C}_{60}{ }^{-}\right)=-1.03 \mathrm{~V}$ versus $\left.\mathrm{Fc}^{\circ+} / \mathrm{Fc}\right)$. These values in $\mathbf{P h}(\mathbf{B P}) \mathbf{C}_{60}$ were 
essentially identical to those of methylphenothiazine $(+0.30 \mathrm{~V})$ and $\mathbf{C}_{60} \mathbf{r e f}(-0.98 \mathrm{~V})$ used as reference compounds, respectively [9-11,13,14]. These results are in good agreement with the absorption spectra which shows no electronic interaction between the $\mathrm{Ph}$ and the $\mathrm{C}_{60}$ moieties in the ground states in $\mathbf{P h}(\mathbf{B P}) \mathbf{C}_{60}$ as described above.

Thermodynamic data for the present intramolecular electron-transfer reactions in $\mathbf{P h}(\mathbf{B P}) \mathbf{C}_{60}$ in two solvents (benzonitrile and benzene) were evaluated as previously reported $[9-11,13,14]$. In the case of benzonitrile, accurate driving forces $\Delta \mathrm{G}\left(\Delta \mathrm{G}_{\mathrm{CR}}, \Delta \mathrm{G}_{\mathrm{CS}}(\mathrm{S})\right.$ and $\left.\Delta \mathrm{G}_{\mathrm{CS}}(\mathrm{T})\right)$ for the intramolecular charge recombination $(\mathrm{CR})$ process from the $\mathrm{C}_{60}$ anion radical $\left(\mathrm{C}_{60}{ }^{-}\right)$to the $\mathrm{Ph}$ cation radical $\left(\mathrm{Ph}^{\cdot+}\right)$ and for the intramolecular charge separation (CS) process from the $\mathrm{Ph}$ to ${ }^{1} \mathrm{C}_{60} *(\mathrm{~S})$ and the triplet excited state of $\mathrm{C}_{60}\left({ }^{3} \mathrm{C}_{60} *\right)(\mathrm{T})$ were calculated using the redox potentials of the $\mathrm{C}_{60}$ and $\mathrm{Ph}$ moieties. The centre-to-centre distance between the $\mathrm{Ph}$ and $\mathrm{C}_{60}$ moieties for $\mathbf{P h}(\mathbf{B P}) \mathbf{C}_{60}$ was estimated to be $21.5 \AA$. The Coulombic term in $\mathbf{P h}(\mathbf{B P}) \mathbf{C}_{60}$ can be negligible because of the high dielectric constant $(\varepsilon=25.2)$ of benzonitrile. In the case of benzene, the free energy changes, $\Delta \mathrm{G}\left(\Delta \mathrm{G}_{\mathrm{CR}}, \Delta \mathrm{G}_{\mathrm{CS}}(\mathrm{S})\right.$ and $\left.\Delta \mathrm{G}_{\mathrm{CS}}(\mathrm{T})\right)$ were calculated from the Rehm-Weller and Born equations using the redox potentials in benzonitrile for convenience [9-11,13,14]. The evaluated Gibbs free energy changes $\Delta \mathrm{G}_{\mathrm{CR}}, \Delta \mathrm{G}_{\mathrm{CS}}(\mathrm{S})$ and $\Delta \mathrm{G}_{\mathrm{CS}}(\mathrm{T})$ were estimated to be $-1.35,-0.41$ and $-0.15 \mathrm{eV}$ in benzonitrile and $2.19,0.43$ and $0.69 \mathrm{eV}$ in benzene. The thermodynamic data for the

intramolecular electron-transfer from $\mathrm{Ph}$ to ${ }^{1} \mathrm{C}_{60} *$ or ${ }^{3} \mathrm{C}_{60} *$ in $\mathbf{P h}(\mathbf{B P}) \mathbf{C}_{\mathbf{6 0}}$ is thermodynamically favourable in benzonitrile, but unfavourable in benzene. This is in good agreement with the fluorescence spectral data (Table 1).

\subsection{Transient absorption spectra in the characterisation of $P h(B P) C_{60}$}


Transient absorption spectra of $\mathbf{P h}(\mathbf{B P}) \mathbf{C}_{60}$ in benzene and benzonitrile were measured to elucidate the photoinduced electron-transfer reactions. Nanosecond laser flash photolysis produced only an absorption band around $700 \mathrm{~nm}$ due to $T_{1}-T_{n}$ absorption of the $\mathrm{C}_{60}$ moiety in benzene, indicating that the photoinduced electrontransfer reaction from $\mathrm{Ph}$ to ${ }^{3} \mathrm{C}_{60} *$ did not occur. Conversely, the decay of the absorption at $700 \mathrm{~nm}$ due to ${ }^{3} \mathrm{C}_{60} *$ and the rise of the absorption at $520 \mathrm{~nm}$ due to $\mathrm{Ph}^{\cdot+}$ were observed in benzonitrile within $100 \mathrm{~ns}$ following the laser pulse at $283 \mathrm{~K}$ in Figure 1. The results indicate that the intramolecular electron-transfer from $\mathrm{Ph}$ to ${ }^{3} \mathrm{C}_{60} *$ occurs, and then the triplet-born biradical is generated and decayed in benzonitrile (Scheme 3). In transient absorption spectra of $\mathbf{P h}(\mathbf{n}) \mathbf{C}_{\mathbf{6 0}}(\mathbf{n}=\mathbf{4 - 1 2})$ in benzonitrile, the rises of the absorption of $\mathrm{Ph}^{\circ+}$ were barely observed [9-14]. Therefore, the rate constant for the intramolecular electron-transfer from $\mathrm{Ph}$ to ${ }^{3} \mathrm{C}_{60} *$ $\left(\mathrm{k}_{\mathrm{CS}}(\mathrm{T})\right.$ in Scheme 3) in $\mathbf{P h}(\mathbf{B P}) \mathbf{C}_{\mathbf{6 0}}$ was smaller than the same rate constant in $\operatorname{Ph}(\mathbf{n}) \mathbf{C}_{60}(\mathbf{n}=4-12)$. In $\mathbf{P h}(\mathbf{B P}) \mathbf{C}_{60}$, the biphenyl group is responsible for the slow electron-transfer due to the suppression of the open-closed motion of the spacer. The results are in good agreement with the effect of the spacer on the quenching of ${ }^{1} \mathrm{C}_{60} *$ (Table 1).

The solvent effect in the transient absorption spectra is in good agreement with the thermodynamic data as described above. These results were in agreement with those of $\mathbf{P h}(\mathbf{n}) \mathbf{C}_{\mathbf{6 0}}(\mathbf{n}=\mathbf{4 - 1 2})$ in both solvents (benzonitrile and benzene) [9$11,13,14]$.

The decay profiles of the transient absorption at $520 \mathrm{~nm}$ due to $\mathrm{Ph}^{\circ+}$ in $\mathbf{P h}(\mathbf{B P}) \mathbf{C}_{60}$ can be expressed by the following equation:

$$
A(t)=A_{1} \exp \left(-k_{C S}(T) t\right)+A_{2} \exp \left(-k_{d} t\right)+C
$$


where, $\mathrm{A}(\mathrm{t})$ is transient absorption at $\mathrm{t}(\mathrm{s}), \mathrm{A}_{1}, \mathrm{~A}_{2}$, and $\mathrm{C}$ are time-independent constants, and $\mathrm{k}_{\mathrm{CS}}(\mathrm{T})\left(\mathrm{s}^{-1}\right)$ and $\mathrm{k}_{\mathrm{d}}\left(\mathrm{s}^{-1}\right)$ are the rate constants for the intramolecular electron-transfer from $\mathrm{Ph}$ to ${ }^{3} \mathrm{C}_{60} *$ and the decay of the biradical, respectively. These parameters were calculated by the non-linear least-squares method. The $\mathrm{k}_{\mathrm{CS}}(\mathrm{T})$-values for $\mathbf{P h}(\mathbf{B P}) \mathbf{C}_{60}$ in benzonitrile were evaluated to be $2.8 \times 10^{7}, 4.2 \times 10^{7}$ and $7.1 \times 10^{7}$ $\mathrm{s}^{-1}$ at 283,303 and $323 \mathrm{~K}$, respectively. However, the $\mathrm{k}_{\mathrm{CS}}(\mathrm{T})$-value cannot be evaluated at $343 \mathrm{~K}$ because of fast electron-transfer. The $\mathrm{k}_{\mathrm{CS}}(\mathrm{T})$-values increased with increasing temperature. The $\mathrm{k}_{C S}(\mathrm{~T})$-values for $\mathbf{P h}(\mathbf{n}) \mathbf{C}_{\mathbf{6 0}}(\mathbf{n}=\mathbf{8}, \mathbf{1 0}, \mathbf{1 2})$ in benzonitrile were evaluated to be $4.7 \times 10^{7}, 4.3 \times 10^{7}$ and $4.2 \times 10^{7} \mathrm{~s}^{-1}$, respectively, by the transient absorption at $1000 \mathrm{~nm}$ due to $\mathrm{C}_{60}{ }^{--}$[23]. The $\mathrm{k}_{\mathrm{CS}}(\mathrm{T})$-values for $\mathbf{P h}(\mathbf{B P}) \mathbf{C}_{60}$ was smaller than those for $\mathbf{P h}(\mathbf{n}) \mathbf{C}_{\mathbf{6 0}}(\mathbf{n}=\mathbf{8}, \mathbf{1 0}, \mathbf{1 2})$. The results also supported the effect of the biphenyl group as discussed above in the transient absorption spectra and the fluorescence spectra.

The $\mathrm{k}_{\mathrm{d}}$-values for $\mathbf{P h}(\mathbf{B P}) \mathbf{C}_{60}$ in benzonitrile were evaluated to be $6.5 \times 10^{6}$, $7.0 \times 10^{6}, 7.2 \times 10^{6}$ and $6.5 \times 10^{6} \mathrm{~s}^{-1}$ at $283,303,323$ and $343 \mathrm{~K}$, respectively. The $\mathrm{k}_{\mathrm{d}}$-value at $343 \mathrm{~K}$ was evaluated by a single exponential decay as previously reported [9-14]. Interestingly, there was only a minor difference in the $\mathrm{k}_{\mathrm{d}}$-values over the range of the experimental temperatures used (283-343 K). The temperature dependence on the $k_{d}$-values is different from that on the $k_{e t}(T)$-values due to the intramolecular electron-transfer. In the case of other methylene systems at $283 \mathrm{~K}$, the $\mathrm{k}_{\mathrm{d}}$-values for $\mathbf{P h}(\mathbf{n}) \mathbf{C}_{\mathbf{6 0}}(\mathbf{n}=\mathbf{4 ,}, \mathbf{6}, \mathbf{8}, \mathbf{1 0}, \mathbf{1 2})$ were estimated to be $5.4 \times 10^{6}, 7.7 \times 10^{6}$, $8.0 \times 10^{6}, 8.9 \times 10^{6}$ and $9.2 \times 10^{6} \mathrm{~s}^{-1}$, respectively [14]. The centre-to-centre distance between the $\mathrm{Ph}$ and $\mathrm{C}_{60}$ moieties for $\mathbf{P h}(\mathbf{B P}) \mathbf{C}_{60}$ was estimated to be $21.0 \AA$ and is expected to be larger than the centre-to-centre distance for $\mathbf{P h}(\mathbf{6}) \mathbf{C}_{\mathbf{6 0}}(18.0 \AA)$ [13]. However, the $\mathrm{k}_{\mathrm{d}}$-value in $\mathbf{P h}(\mathbf{B P}) \mathbf{C}_{\mathbf{6 0}}$ was obviously smaller than that in $\mathbf{P h}(\mathbf{6}) \mathbf{C}_{\mathbf{6 0}}$. 
The $\mathrm{k}_{\mathrm{d}}$-value of the photogenerated biradical via ${ }^{3} \mathrm{C}_{60} *$ at zero magnetic field is determined by the sum of the rate constants for the intersystem crossing from the triplet biradical to the singlet one $\left(\mathrm{k}_{\mathrm{isc} 2}\right)$ or the back electron-transfer from the singlet biradical to the ground state $\left(\mathrm{k}_{\mathrm{bet}}\right)$, and the spin-orbit coupling (SOC) induced intersystem crossing rate $\left(\mathrm{k}_{\mathrm{SOC}}\right)$ as shown in Scheme 3. The temperature effect on the $\mathrm{k}_{\mathrm{d}}$-values for $\mathbf{P h}(\mathbf{B P}) \mathbf{C}_{60}$ are discussed below.

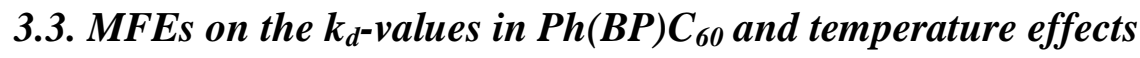

The MFEs on the transient absorption spectra in $\mathbf{P h}(\mathbf{B P}) \mathbf{C}_{60}$ were examined in benzene and benzonitrile. No MFEs in the transient absorption were observed in benzene. The result is consistent with the observation that the triplet-born biradical is not generated by electron-transfer from $\mathrm{Ph}$ to ${ }^{3} \mathrm{C}_{60} *\left(\mathrm{k}_{\mathrm{CS}}(\mathrm{T})\right.$ in Scheme 3) in benzene.

The MFEs on the photoinduced electron-transfer in $\mathbf{P h}(\mathbf{B P}) \mathbf{C}_{\mathbf{6 0}}$ were also examined in benzonitrile in the range of $283-343 \mathrm{~K}$. In the presence of a magnetic field, the decay profiles of the transient absorption at $520 \mathrm{~nm}$ were suppressed in a lower magnetic field at $0.1 \mathrm{~T}$ and then accelerated at $1.0 \mathrm{~T}$ at $283 \mathrm{~K}$ (Figure 2(a)). Similar MFEs were observed at $343 \mathrm{~K}$ (Figure 2(b)). Figure 3 displays the temperature dependence of the MFEs on the $\mathrm{k}_{\mathrm{d}}$-values for $\mathbf{P h}(\mathbf{B P}) \mathbf{C}_{\mathbf{6 0}}$. In Figure 3, with increasing magnetic fields the $\mathrm{k}_{\mathrm{d}}$-values decreased in the region of $0-0.2 \mathrm{~T}$ and gradually increased in the region of $0.2-1 \mathrm{~T}$, leading to the reverse phenomena in the MFEs. The reverse phenomena obviously changed with increasing temperature (Figure 3). Similar phenomena were obtained in the cases of the linked compounds with flexible methylene groups, $\mathbf{P h}(\mathbf{n}) \mathbf{C}_{60}(\mathbf{n}=4-12)[12-14]$ and $\mathbf{Z n P}(\mathbf{n}) \mathbf{C}_{60}(\mathbf{n}=\mathbf{4}$, 8) $[15,16]$. However, the $\mathrm{k}_{\mathrm{CS}}(\mathrm{T})$-values at 283,303 and $323 \mathrm{~K}$ were not influenced by 
the magnetic field because the intramolecular electron-transfer from $\mathrm{Ph}$ to ${ }^{3} \mathrm{C}_{60} *$ is independent of the magnetic field strength.

The minimum $\mathrm{k}_{\mathrm{d}^{-}}$-value at $0.1-0.2 \mathrm{~T}$ in $\mathbf{P h}(\mathbf{B P}) \mathbf{C}_{\mathbf{6 0}}$ is smaller than the values in $\mathbf{P h}(\mathbf{n}) \mathbf{C}_{60}(\mathbf{n}=\mathbf{4 - 1 2})[12-14]$ at the same temperature. $\operatorname{In} \mathbf{P h}(\mathbf{n}) \mathbf{C}_{60}(\mathbf{n}=\mathbf{4 - 1 2})$, the minimum $\mathrm{k}_{\mathrm{d}}$-value at $0.1-0.2 \mathrm{~T}$ has been shown to increase with increasing temperature [12-14]. In contrast, in $\mathbf{P h}(\mathbf{B P}) \mathbf{C}_{\mathbf{6 0}}$, the minimum $\mathrm{k}_{\mathrm{d}}$-value at $0.1-0.2 \mathrm{~T}$ was essentially constant above $303 \mathrm{~K}$ (Figure 3 ). The minimum $\mathrm{k}_{\mathrm{d}}$-value is dominated by the $\mathrm{k}_{\mathrm{SOC}}$-value. Hence, the results show that the contribution of the SOC in $\mathbf{P h}(\mathbf{B P}) \mathbf{C}_{60}$ is smaller than the SOC in $\mathbf{P h}(\mathbf{n}) \mathbf{C}_{60}(\mathbf{n}=\mathbf{6 - 1 2})$ due to the difference in the rigidity of the spacer between the $\mathrm{Ph}$ and $\mathrm{C}_{60}$ moieties. Furthermore, temperature effects on the reverse phenomena of the MFEs in $\mathbf{P h}(\mathbf{B P}) \mathbf{C}_{\mathbf{6 0}}$ implied that the $\mathrm{k}_{\mathrm{d}^{-}}$ values in the presence of the magnetic field are controlled by spin relaxation $\left(\mathrm{k}_{\mathrm{sr}}\right)$, which is caused by molecular motion.

\subsection{Mechanism of the MFEs}

The MFEs for a biradical can be explained by spin rephasing $(\Delta \mathrm{g})$, hyperfine coupling (hfc), S-T level crossing, and spin-lattice (SLR) and spin-spin relaxation (SSR) mechanisms [6-8]. The photoinduced electron-transfer and the MFEs in $\mathbf{P h}(\mathbf{B P}) \mathbf{C}_{60}$ were examined in benzonitrile at various temperatures for verifying the mechanism of the novel MFEs as described above. The novel MFEs in $\mathbf{P h}(\mathbf{B P}) \mathbf{C}_{\mathbf{6 0}}$ and $\mathbf{P h}(\mathbf{n}) \mathbf{C}_{60}(\mathbf{n}=\mathbf{6}-\mathbf{1 2})$ are discussed below.

The MFEs on the $\mathrm{k}_{\mathrm{d}}$-values in the range of $0-1 \mathrm{~T}$ can be separated into two parts: lower magnetic fields below $0.1-0.2 \mathrm{~T}$ and higher magnetic fields above 0.1-0.2 T. The magnitudes of the MFEs in $\mathbf{P h}(\mathbf{B P}) \mathbf{C}_{\mathbf{6 0}}$ and $\mathbf{P h}(\mathbf{n}) \mathbf{C}_{\mathbf{6 0}}(\mathbf{n}=\mathbf{6}-\mathbf{1 2})$ were 
evaluated by the ratios at the lower magnetic fields $\left(\Delta_{\text {low }}=\mathrm{k}_{\mathrm{d}}(0 \mathrm{~T}) / \mathrm{k}_{\mathrm{d}}(0.2 \mathrm{~T})\right.$ at 283 and $303 \mathrm{~K}$ and $\Delta_{\text {low }}=\mathrm{k}_{\mathrm{d}}(0 \mathrm{~T}) / \mathrm{k}_{\mathrm{d}}(0.1 \mathrm{~T})$ at 323 and $\left.343 \mathrm{~K}\right)$ and at the higher magnetic fields $\left(\Delta_{\text {high }}=\mathrm{k}_{\mathrm{d}}(1.0 \mathrm{~T}) / \mathrm{k}_{\mathrm{d}}(0.2 \mathrm{~T})\right.$ at 283 and $303 \mathrm{~K}$ and $\Delta_{\text {high }}=\mathrm{k}_{\mathrm{d}}(1.0 \mathrm{~T}) / \mathrm{k}_{\mathrm{d}}(0.1 \mathrm{~T})$ at 323 and $343 \mathrm{~K}$ ) reported in previous works [12-14].

In the case of $\mathbf{P h}(\mathbf{B P}) \mathbf{C}_{60}$ and $\mathbf{P h}(\mathbf{n}) \mathbf{C}_{60}(\mathbf{n}=\mathbf{6 - 1 2})$, the MFEs in lower magnetic fields $(<0.2 \mathrm{~T})$ are explained by both of isotropic hfc and SLR mechanisms as reported previously [9-14]. The isotropic hfc mechanism can be discussed by a semitheoretical value $\left(B_{1 / 2}\right)$ of the half width of the MFEs, where $B_{1 / 2}$ is given by $B_{1 / 2}$ $=2\left(\mathrm{~B}_{1}^{2}+\mathrm{B}_{2}^{2}\right) /\left(\mathrm{B}_{1}+\mathrm{B}_{2}\right)$, and $\mathrm{B}_{1}$ and $\mathrm{B}_{2}$ refer to the hyperfine interaction between the nuclear spins and unpaired electron spins in each radical [4]. The hfc constant of the $\mathrm{C}_{60}$ moiety with a substituent was neglected since the $\mathrm{C}_{60}$ moiety component of $\mathrm{B}_{1 / 2^{-}}$ value is evaluated to be below $0.1 \mathrm{mT}$ [19]. The $\mathrm{B}_{1 / 2}$-value is estimated to be $2.4 \mathrm{mT}$ only using the hfc constants of the $\mathrm{Ph}^{\cdot+}$ [23]. This-value is smaller than the experimental value (7.5 mT) [9]. Therefore, the MFEs in lower magnetic fields $(<0.2$ T) cannot be explained only by isotropic hfc mechanism. The MFEs in lower magnetic fields $(<0.2 \mathrm{~T})$ in $\mathbf{P h}(\mathbf{n}) \mathbf{C}_{\mathbf{6 0}}(\mathbf{n}=\mathbf{6 - 1 2})$ can be interpreted in terms of isotropic hfc $(\mathrm{H}<$ ca. $5 \mathrm{mT})$ and SLR mechanism due to anisotropic hyperfine and dipole-dipole interactions (ca. $5 \mathrm{mT}<\mathrm{H}<0.2 \mathrm{~T}$ ) [9-14].

The $\Delta_{\text {low }}$-values in $\mathbf{P h}(\mathbf{n}) \mathbf{C}_{\mathbf{6 0}}(\mathbf{n}=\mathbf{6}-\mathbf{1 2})$ are determined by two mechanisms: the dramatic decrease in the $0-0.05 \mathrm{~T}$ region is due to the isotropic hfe mechanism and the gradual one in the $0.05-0.2 \mathrm{~T}$ region is due to the SLR mechanism which is dependent on the anisotropic hyperfine or dipole-dipole interactions [9-14].

The MFEs up to about $0.2 \mathrm{~T}$ in $\mathbf{P h}(\mathbf{B P}) \mathbf{C}_{60}$ can be also explained in terms of the above two mechanisms. The $\Delta_{\text {low-values in }} \mathbf{P h}(\mathbf{B P}) \mathbf{C}_{60}$ at $283,303,323$ and $343 \mathrm{~K}$ were estimated to be $1.77,1.63,1.59$ and 1.47 , respectively. The $\Delta_{\text {low }}$-value in 
$\mathbf{P h}(\mathbf{B P}) \mathbf{C}_{60}$ was reduced by 1.20 times on going from 283 to $343 \mathrm{~K}$. The reduction of $\Delta_{\text {low }}$-value due to temperature in $\mathbf{P h}(\mathbf{B P}) \mathbf{C}_{\mathbf{6 0}}$ was smaller than those $(1.41 \sim 1.56$ times) reported for $\mathbf{P h}(\mathbf{n}) \mathbf{C}_{\mathbf{6 0}}(\mathbf{n}=\mathbf{6}-\mathbf{1 2})$ as shown in Figure 4 (a). The results show that the contribution of the SLR mechanism caused by the dipole-dipole interaction is quite small in $\mathbf{P h}(\mathbf{B P}) \mathbf{C}_{\mathbf{6 0}}$ because the closed state of the biradical does not exist due to the rigidity of the spacer moiety of $\mathbf{P h}(\mathbf{B P}) \mathbf{C}_{\mathbf{6 0}}$.

In the high magnetic field region, the $\mathrm{k}_{\mathrm{d}}$-values increased with increasing magnetic field. The MFEs can be explained by three mechanisms: $\Delta \mathrm{g}$ mechanism, $\mathrm{S}-$ T. level-crossing mechanism, and SLR and SSR mechanisms due to $\delta \mathrm{g}$ interaction. First, $\Delta \mathrm{g}$ mechanism can be ineffective in the magnetic field below $1 \mathrm{~T}$ from the $\mathrm{g}$ values of $\mathrm{Ph}^{*+}(\mathrm{g}=2.0052)$ [24] and $\mathrm{C}_{60}{ }^{--}(\mathrm{g}=1.9982)$ [25] radicals [9-14]. Second, the magnetic field strength at which S-T. level crossing takes place represent the effective exchange interaction $(|2 \mathrm{~J}|)$ of the biradical [6-8]. Therefore, the reverse phenomena in the MFEs in $\mathbf{P h}(\mathbf{B P}) \mathbf{C}_{60}$ and $\mathbf{P h}(\mathbf{n}) \mathbf{C}_{60}(\mathbf{n}=\mathbf{6}-12)$ [12-14] cannot be explained by S-

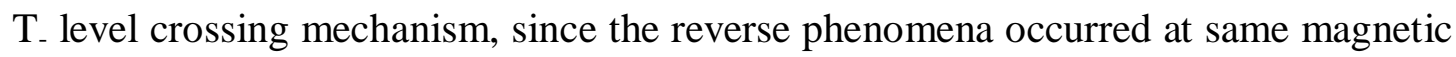
field ( $0.2 \mathrm{~T})$ in $\mathbf{P h}(\mathbf{B P}) \mathbf{C}_{60}$ and $\mathbf{P h}(\mathbf{n}) \mathbf{C}_{60}(\mathbf{n}=\mathbf{6}-\mathbf{- 1 2})$ in spite of the different exchange interaction $(|2 \mathrm{~J}|)$. Third, if the large anisotropy of g-tensor is assumed in $\operatorname{Ph}(\mathbf{B P}) \mathbf{C}_{60}$ and $\operatorname{Ph}(\mathbf{n}) \mathbf{C}_{60}(\mathbf{n}=\mathbf{6}-12)$, the MFEs in the high magnetic field region $(>0.2 \mathrm{~T})$ may be explained by the contribution of SLR mechanism due to $\delta \mathrm{g}$ interaction [14]. However, it is difficult for $\mathbf{P h}(\mathbf{B P}) \mathbf{C}_{60}$ and $\mathbf{P h}(\mathbf{n}) \mathbf{C}_{60}(\mathbf{n}=\mathbf{6 - 1 2})$ to have a high-anisotropy of g-tensor since the mean value for the inner product of the anisotropic g-tensor, $(\mathrm{g}: \mathrm{g})_{\mathrm{av}}=6.93 \times 10^{-6}$ is small [26]. Therefore, the MFEs $(>0.2 \mathrm{~T})$ in $\mathbf{P h}(\mathbf{B P}) \mathbf{C}_{60}$ and $\mathbf{P h}(\mathbf{n}) \mathbf{C}_{60} \quad(\mathbf{n}=\mathbf{6}-12)$ [12-14] cannot be explained by SLR mechanisms due to $\delta g$ interaction. Finally, the MFEs in higher magnetic fields in 
$\mathbf{P h}(\mathbf{B P}) \mathbf{C}_{60}$ and $\mathbf{P h}(\mathbf{n}) \mathbf{C}_{60}(\mathbf{n}=\mathbf{6}-\mathbf{1 2})$ are most likely explained by SSR mechanism due to $\delta \mathrm{g}$ interaction.

In higher magnetic fields (>0.2 T) in $\mathbf{P h}(\mathbf{B P}) \mathbf{C}_{\mathbf{6 0}}$, the $\Delta_{\text {high }}$-values at 283, 303, 323 and $343 \mathrm{~K}$ were $1.15,1.17,1.25$ and 1.36 , respectively. The $\Delta_{\text {high-value was }}$ enhanced by 1.18-times on going from 283 to $343 \mathrm{~K}$. The effect of temperature on the $\Delta_{\text {high }}$ in $\mathbf{P h}(\mathbf{B P}) \mathbf{C}_{60}$ was similar to that in $\mathbf{P h}(\mathbf{n}) \mathbf{C}_{60}(\mathbf{n}=\mathbf{6}-\mathbf{1 2})$ in Figure 4 (b), despite the different spacer motion. The results suggest that the MFEs in high magnetic fields observed in $\mathbf{P h}(\mathbf{B P}) \mathbf{C}_{60}$ are governed by both SLR and SSR mechanisms due to the $\delta \mathrm{g}$ interaction, which was also observed for $\mathbf{P h}(\mathbf{n}) \mathbf{C}_{60}(\mathbf{n}=\mathbf{6}-\mathbf{1 2})$.

According to the SSR mechanism due to the $\delta \mathrm{g}$ interaction, a rate constant $\mathrm{k}_{\mathrm{SSR}}(\delta \mathrm{g})$ is expressed as follow [7, 20]:

$$
\mathrm{k}_{\mathrm{SSR}}(\delta \mathrm{g}) \propto(\mathrm{g}: \mathrm{g})_{\mathrm{av}}{ }^{2} \beta^{2} \mathrm{H}^{2} \tau_{\mathrm{c}, \mathrm{av}} /\left\{1+\gamma^{2} \tau_{\mathrm{c}, \mathrm{av}}{ }^{2}(2 \mathrm{~J})^{2}\right\}
$$

where $\gamma,(\mathrm{g}: \mathrm{g})_{\mathrm{av}}$ and $\tau_{\mathrm{c}, \mathrm{av}}$ are the magnetogyric ratio of the electron, mean values for the inner product of the anisotropic $\mathrm{g}$ tensor and the correlation time for the $\delta \mathrm{g}$ interaction, respectively, averaged in two radicals. $\beta$ denotes the Bohr magnetron. Thus, if the MFEs are interpreted by the SSR mechanism due to the $\delta \mathrm{g}$ interaction, the $\mathrm{k}_{\mathrm{d}}$-values should be given by Equation (2) and be proportional to the square of the magnetic field $\left(\mathrm{H}^{2}\right)$.

Plots of $k_{d}$ versus $H^{2}$ in $\mathbf{P h}(\mathbf{B P}) \mathbf{C}_{60}$ are shown in Figure 5. At low temperatures (283 and $303 \mathrm{~K})$, good linear relationships ( $\mathrm{R}=0.86$ and 0.98$)$ were observed for the magnetic fields $\left(0.04-0.64 \mathrm{~T}^{2}\right)$ and strongly imply that the MFEs in lower magnetic fields are governed by the SSR mechanism. At high temperatures (323 and $343 \mathrm{~K})$, good linear relationships $(\mathrm{R}=0.99$ and 0.99$)$ were observed in magnetic fields $\left(0.01-0.36 \mathrm{~T}^{2}\right)$, whereas such linear relationships were not observed 
for higher magnetic fields $(0.8-1 \mathrm{~T})$. The disappearance of the linear relationship is probably caused by the $\mathrm{k}_{\mathrm{d}}$-values at high magnetic fields $(>0.8 \mathrm{~T})$ being dominated by both the SSR and the SLR mechanisms due to the $\delta \mathrm{g}$ interaction. The effects of the high magnetic field above $1 \mathrm{~T}$ require further characterisation for clarifying the contribution of the SLR due to the $\delta g$ interaction.

\subsection{Time-resolved EPR spectra for $P h(B P) C_{60}$}

For the photogenerated triplet-born biradical $\left(\mathrm{Ph}^{{ }^{+}-} \mathrm{C}_{60}{ }^{\circ}\right)$ of $\mathbf{P h}(\mathbf{B P}) \mathbf{C}_{60}$ in benzonitrile, the presence of an appreciable electron spin-spin exchange and dipoledipole interactions is expected. As a consequence, time-resolved EPR spectra with the characteristic antiphase would be observed as reported for well-known spin-correlated radical pairs $[27,28]$. We have previously observed the time-resolved EPR spectra due to spin-correlated radical pairs in $\mathbf{P h}(\mathbf{n}) \mathbf{C}_{\mathbf{6 0}}(\mathbf{n}=\mathbf{4 - 1 2})[11,14]$ and $\mathbf{Z n P}(\mathbf{n}) \mathbf{C}_{60}(\mathbf{n}$ $=4,8)[16]$ in benzonitrile. Since comparison between time-resolved EPR spectra of $\operatorname{Ph}(\mathbf{B P}) \mathbf{C}_{60}$ and $\mathbf{P h}(\mathbf{n}) \mathbf{C}_{60}(\mathbf{n}=$ 4-12) provides further information on the spin dynamics of the photogenerated biradical in $\mathrm{Ph}-\mathrm{C}_{60}$ linked systems, we measured the time-resolved EPR spectrum of $\mathbf{P h}(\mathbf{B P}) \mathbf{C}_{60}$ at room temperature in benzene and benzonitrile.

In the time-resolved EPR spectrum of $\mathbf{P h}(\mathbf{B P}) \mathbf{C}_{\mathbf{6 0}}$ in benzene, only the absorption pattern at $\mathrm{g}=2.0013$ was observed. The signals rose initially in the $0-0.5$ $\mu$ s region and subsequently decayed in the $1.0-10 \mu$ s region and was similar to those of $\mathbf{C}_{60}$ ref, carbazole- $C_{60}$ linked compound, $\mathbf{P h}(\mathbf{n}) \mathbf{C}_{60}(\mathbf{n}=\mathbf{4 - 1 2})[11,14]$ and $\operatorname{ZnP}(n) \mathbf{C}_{60}(\mathbf{n}=4,8)$ [16]. Consequently, the spectra of $\mathbf{P h}(\mathbf{B P}) \mathbf{C}_{60}$ in benzene can be assigned to ${ }^{3} \mathrm{C}_{60} *$. The results in the time-resolved EPR measurements are consistent 
with the reaction mechanism obtained from the transient absorption spectra and the MFEs in benzene.

Time-resolved EPR spectra of $\mathbf{P h}(\mathbf{B P}) \mathbf{C}_{\mathbf{6 0}}$ in benzonitrile at room temperature are shown in Figure 6. The time-resolved EPR spectra, which consisted of absorption (A), emission (E), (strong) absorption (A*) and emission (E) pattern, were observed in all time domains. The signals rose initially in the $0-0.5 \mu$ s region and subsequently decayed in the $0.5-1 \mu$ s region. In same time region $(\sim 1 \mu \mathrm{s})$, the triplet-born biradicals were observed in the transient absorption spectra as described above. Therefore, the spectra in $\mathbf{P h}(\mathbf{B P}) \mathbf{C}_{\mathbf{6 0}}$ in benzonitrile can be assigned to spincorrelated radical pairs (SCRP) generated by the photoinduced intramolecular electron-transfer from $\mathrm{Ph}$ to ${ }^{3} \mathrm{C}_{60}{ }^{*}$. In the previous studies, time-resolved EPR spectra in methylene systems gave E/A patterns in $\mathbf{P h}(\mathbf{n}) \mathbf{C}_{\mathbf{6 0}}(\mathbf{n}=\mathbf{4 - 1 2})[11,14]$ and in $\operatorname{ZnP}(n) \mathbf{C}_{60}(\mathbf{n}=\mathbf{4}, \mathbf{8})[16]$. It is very interesting that the $\mathrm{A} / \mathrm{E} / \mathrm{A} * / \mathrm{E}$ patterns in $\mathbf{P h}(\mathbf{B P}) \mathbf{C}_{60}$ (Figure 6) were quite different from the E/A patterns in $\mathbf{P h}(\mathbf{n}) \mathbf{C}_{60}(\mathbf{n}=$ 4-12) and $\mathbf{Z n P}(n) \mathbf{C}_{60}(n=4,8)$ in the time-resolved EPR spectra.

The time-resolved EPR spectra consisting of $\mathrm{A} / \mathrm{E} / \mathrm{A} / \mathrm{E}$ patterns in $\mathbf{P h}(\mathbf{B P}) \mathbf{C}_{60}$ can be explained by of the overlapping SCRP signals of the $\mathrm{Ph}^{\circ+}$ component in lower magnetic fields and the $\mathrm{C}_{60}{ }^{-}$one in higher magnetic fields. The semi-rigid bridge in $\mathbf{P h}(\mathbf{B P}) \mathbf{C}_{60}$ can lead to suppression of the open-closed motion and only the open state of the spacer is produced. On the other hand, the flexibility of methylene chain can make the open-closed motion more active in $\mathbf{P h}(\mathbf{n}) \mathbf{C}_{\mathbf{6 0}}(\mathbf{n}=$ 4-12) and $\operatorname{ZnP}(n) C_{60}(n=4,8)$. Accordingly the reason that each SCRP signal was separately observed in $\mathbf{P h}(\mathbf{B P}) \mathbf{C}_{60}$ can be assigned to the smaller magnitude and distribution of the $|2 \mathrm{~J}|$ in $\mathbf{P h}(\mathbf{B P}) \mathbf{C}_{\mathbf{6 0}}$ in comparison with those in $\mathbf{P h}(\mathbf{n}) \mathbf{C}_{\mathbf{6 0}}(\mathbf{n}=\mathbf{4 - 1 2})$ and $\operatorname{ZnP}(n) \mathbf{C}_{60}(\mathbf{n}=\mathbf{4}, \mathbf{8})$. The E/A patterns observed in the methylene chain systems 
$\left(\operatorname{Ph}(n) C_{60}(n=4-12)\right.$ and $\left.\operatorname{ZnP}(n) C_{60}(n=4,8)\right)$ may be interpreted in terms of the averaging of the two radical components caused by the larger distribution of the $|2 \mathrm{~J}|$ in the methylene chain systems. Thus the time-resolved EPR spectra observed in $\operatorname{Ph}(\mathbf{B P}) \mathbf{C}_{60}$ and $\mathbf{P h}(\mathbf{n}) \mathbf{C}_{60}(\mathbf{n}=\mathbf{4 - 1 2})$ are strongly affected by the difference in the motion of the spacer.

The observation of the $\mathrm{A} / \mathrm{E} / \mathrm{A} * / \mathrm{E}$ patterns means that the sign of the $\mathrm{J}$ of $\mathbf{P h}(\mathbf{B P}) \mathbf{C}_{60}$ is positive since transient absorption spectra and the MFEs showed tripletborn biradicals. The energy gap dependence for the electron-transfer can be estimated using the Marcus theory [29]. The total reorganization energy $\lambda$ is the sum of an internal contribution $\left(\lambda_{\mathrm{i}}(0.16 \mathrm{eV})\right)[16]$ and a solvent contribution $\left(\lambda_{\mathrm{s}}\right)$. In benzonitrile, the $\lambda$ value for $\mathbf{P h}(\mathbf{B P}) \mathbf{C}_{\mathbf{6 0}}$ was calculated to be $1.08 \mathrm{eV}$ by using the two-sphere model $[30,31]$. The $-\Delta \mathrm{G}_{\mathrm{CR}}$-value estimated using the redox potentials is $1.35 \mathrm{eV}$ in benzonitrile and the $-\Delta \mathrm{G}_{\mathrm{CR}}$-value is larger than the $\lambda$ value $(1.08 \mathrm{eV})$. Therefore, the charge recombination in $\mathbf{P h}(\mathbf{B P}) \mathbf{C}_{60}$ is expected to occur in the inverted region in the Marcus theory.

On the other hand, the $-\Delta \mathrm{G}_{\mathrm{CS}}(\mathrm{S})-$ and $-\Delta \mathrm{G}_{\mathrm{CS}}(\mathrm{T})$-values are 0.41 and $0.15 \mathrm{eV}$, and $-\Delta \mathrm{G}_{\mathrm{CS}}(\mathrm{S})$ - and $-\Delta \mathrm{G}_{\mathrm{CS}}(\mathrm{T})$-values are smaller than the $\lambda$ value $(1.08 \mathrm{eV})$. Hence, the intramolecular electron-transfer reactions occur in the normal region according to the Marcus theory.

Tero-kubota and Kobori et al. have reported that the $\mathrm{J}$ of a radical pair state is dominated by the electronic coupling perturbation from the charge-recombined ground state in the triplet reaction precursor system $[32,33]$. Since the sign of the $\mathbf{J}$ gave a positive value, this strongly supports the notion that the charge recombination in $\mathbf{P h}(\mathbf{B P}) \mathbf{C}_{60}$ occurs in the inverted region in Marcus theory. This consideration is in fair agreement with the $\mathrm{A} / \mathrm{E} / \mathrm{A}^{*} / \mathrm{E}$ patterns (Figure 6) in the time-resolved $\mathrm{EPR}$ 
spectra of $\mathbf{P h}(\mathbf{B P}) \mathbf{C}_{60}$. We cannot observe the MFEs if the intramolecular charge recombination is slower than the intersystem crossing. At least, the charge recombination from the singlet biradical is expected to be above $6-7 \times 10^{6} \mathrm{~s}^{-1}\left(\mathrm{k}_{\mathrm{d}^{-}}\right.$ values at 283, 303, 323 and $343 \mathrm{~K}$ ) because the MFEs can be observed.

\section{Conclusion}

Spectroscopic and electrochemical properties of a $\mathrm{Ph}-\mathrm{C}_{60}$ linked compound with a biphenyl group as a semi-rigid spacer $\left(\mathbf{P h}(\mathbf{B P}) \mathbf{C}_{\mathbf{6 0}}\right)$ were performed in benzonitrile (polar solvent) and benzene (non-polar solvent).

Absorption spectra of $\mathbf{P h}(\mathbf{B P}) \mathbf{C}_{\mathbf{6 0}}$ in benzene and benzonitrile indicated no appreciable electronic interactions between the $\mathrm{Ph}$ and the $\mathrm{C}_{60}$ moieties, and this observation is similar to the results with $\mathrm{Ph}-\mathrm{C}_{60}$ compounds with flexible methylene group linkers $\left(\mathbf{P h}(\mathbf{n}) \mathbf{C}_{60}(\mathbf{n}=\mathbf{4 - 1 2})\right)$. The fluorescence spectra of $\mathbf{P h}(\mathbf{B P}) \mathbf{C}_{60}$ and $\mathbf{P h}(\mathbf{1 0}) \mathbf{C}_{60}$ indicated that ${ }^{1} \mathrm{C}_{60} *$ was quenched by photoinduced intramolecular electron-transfer from $\mathrm{Ph}$ to ${ }^{1} \mathrm{C}_{60} *$. The relative fluorescence intensity for $\mathbf{P h}(\mathbf{B P}) \mathbf{C}_{60}$ was larger than that for $\mathbf{P h}(\mathbf{1 0}) \mathbf{C}_{\mathbf{6 0}}$, although the distance between $\mathrm{Ph}$ and $\mathrm{C}_{60}$ moieties for $\mathbf{P h}(\mathbf{B P}) \mathbf{C}_{60}$ was slightly shorter than for the same distance estimated for $\mathbf{P h}(\mathbf{1 0}) \mathbf{C}_{60}$. This observation suggests that the quenching of ${ }^{1} \mathbf{C}_{60} *$ for $\mathbf{P h}(\mathbf{B P}) \mathbf{C}_{60}$ was suppressed by the rigidity of the biphenyl group linker compared with the flexible methylene linker in $\mathbf{P h}(\mathbf{1 0}) \mathbf{C}_{\mathbf{6 0}}$.

The transient absorption spectra in $\mathbf{P h}(\mathbf{B P}) \mathbf{C}_{60}$ indicate that the intramolecular electron-transfer from $\mathrm{Ph}$ to ${ }^{3} \mathrm{C}_{60} *$ occurs and then the biradicals are generated in benzonitrile, whereas generation of the biradicals did not occur in benzene. The results are similar to those in $\mathbf{P h}(\mathbf{n}) \mathbf{C}_{60}(\mathbf{n}=\mathbf{4 - 1 2})$. In contrast, the rise of the absorption due to $\mathrm{Ph}^{\cdot+}$ was observed for $\mathbf{P h}(\mathbf{B P}) \mathbf{C}_{60}$ in benzonitrile, whereas the 
behaviour was barely observed in other linked compounds with flexible methylene groups $\left(\mathbf{P h}(\mathbf{n}) \mathbf{C}_{60}(\mathbf{n}=\mathbf{4 - 1 2})\right)$. The results indicate that the biphenyl group is responsible for the slow electron-transfer from $\mathrm{Ph}$ to ${ }^{3} \mathrm{C}_{60} *$ due to the suppression of the open-closed motion of the spacer in $\mathbf{P h}(\mathbf{B P}) \mathbf{C}_{\mathbf{6 0}}$. The results are in good agreement with the data describing the quenching of ${ }^{1} \mathrm{C}_{60} *$.

The MFEs on the $\mathrm{k}_{\mathrm{d}^{-}}$-values in $\mathbf{P h}(\mathbf{B P}) \mathbf{C}_{\mathbf{6 0}}$ were examined in benzonitrile in the range of $283-343 \mathrm{~K}$. The $\mathrm{k}_{\mathrm{d}}$-values of the photogenerated biradical decreased in the $0-0.2 \mathrm{~T}$ magnetic field range and increased in the $0.2-1 \mathrm{~T}$ magnetic field range. The reverse phenomena of the MFEs in $\mathbf{P h}(\mathbf{B P}) \mathbf{C}_{60}$ were strongly enhanced with increasing temperature and similar to those of $\mathbf{P h}(\mathbf{n}) \mathbf{C}_{\mathbf{6 0}}(\mathbf{n}=\mathbf{6 - 1 2})$ with the flexible methylene groups. The results show that the MFEs in $\mathbf{P h}(\mathbf{B P}) \mathbf{C}_{\mathbf{6 0}}$ can be governed by SLR and SSR mechanisms due to the $\delta$ g interaction regardless of a semi-rigid bridge.

Time-resolved EPR spectra of $\mathbf{P h}(\mathbf{B P}) \mathbf{C}_{\mathbf{6 0}}$ in benzonitrile showed the $\mathrm{A} / \mathrm{E} / \mathrm{A}^{*} / \mathrm{E}$ patterns, indicating that the EPR spectra in $\mathbf{P h}(\mathbf{B P}) \mathbf{C}_{\mathbf{6 0}}$ in benzonitrile can be assigned to spin-correlated radical pairs (SCRP). The results can be explained by the overlap of the SCRP signals of the $\mathrm{Ph}^{\circ+}$ component at the lower magnetic fields and the $\mathrm{C}_{60}{ }^{--}$component at the higher magnetic fields. Interestingly, the observed $\mathrm{A} / \mathrm{E} / \mathrm{A} * / \mathrm{E}$ patterns in $\mathbf{P h}(\mathbf{B P}) \mathbf{C}_{\mathbf{6 0}}$ were quite different from the $\mathrm{E} / \mathrm{A}$ patterns of $\operatorname{Ph}(n) C_{60}(n=4-12)$ and $\operatorname{ZnP}(n) C_{60}(n=4,8)$ observed in previous work. On the basis of the spacer motion, the reason that well-defined SCRP signals were separately observed in $\mathbf{P h}(\mathbf{B P}) \mathbf{C}_{\mathbf{6 0}}$ is because of the smaller magnitude and distribution of the $|2 \mathrm{~J}|$ in $\mathbf{P h}(\mathbf{B P}) \mathbf{C}_{60}$ when compared with the magnitudes and distribution of the $|2 \mathrm{~J}|$ in methylene chain systems $\left(\mathbf{P h}(\mathbf{n}) \mathbf{C}_{\mathbf{6 0}}(\mathbf{n}=\mathbf{4 - 1 2})\right.$ and $\left.\mathbf{Z n P}(\mathbf{n}) \mathbf{C}_{60}(\mathbf{n}=\mathbf{4}, \mathbf{8})\right)$. The $\mathrm{A} / \mathrm{E} / \mathrm{A} * / \mathrm{E}$ patterns suggest that the sign of the $\mathbf{J}$ of $\mathbf{P h}(\mathbf{B P}) \mathbf{C}_{60}$ is positive. The results strongly indicate that the charge recombination in $\mathbf{P h}(\mathbf{B P}) \mathbf{C}_{\mathbf{6 0}}$ occurs in the inverted 
region and is agreement with energy gap dependence of electron-transfer reactions in the correlation of $-\Delta \mathrm{G}_{\mathrm{CR}}$ and $\lambda$. Further quantitative investigations on the timeresolved EPR in $\mathrm{Ph}-\mathrm{C}_{60}$ linked systems are currently in progress.

\section{Acknowledgements}

The authors are grateful to Mr. H. Horiuchi for the preparation of quartz cells for transient absorption spectra and time-resolved EPR experiments. The authors are grateful to Mr. Hironobu Tahara for the RM1 calculations. The authors thank Professor Seigo Yamauchi (Tohoku University) and Professor Yasuhiro Kobori (Shizuoka University) for their helpful discussions and useful suggestions regarding the time-resolved EPR spectra. The authors also thank the Center of Advanced Instrumental Analysis, Kyushu University, for ${ }^{1} \mathrm{H}-\mathrm{NMR}$ measurements. The present study was supported by Grants-in-Aid for Scientific Research on the Priority Area of "Super-Hierarchical Structures" (Area 446, No. 19022027), Scientific Research C (Nos. 17550131 and 21550135), Nanotechnology Network Project (Kyushu-area Nanotechnology Network) and Global COE Program "Science for Future Molecular Systems" from the Ministry of Education, Culture, Sports, Science and Technology of Japan. 
References

[1] D. M. Guldi and M. Prato, Acc. Chem. Res. 33, 695 (2000).

[2] H. Imahori, Org. Biomol. Chem. 2, 1425 (2004).

[3] H. Imahori, Bull. Chem. Soc. Jpn. 80, 621 (2007).

[4] H. Kawauchi, S. Suzuki, M. Kozaki, K. Okada, D.-M. S. Islam, Y. Araki, O. Ito, and K. Yamanaka, J. Phys. Chem. A 112, 5878 (2008).

[5] S. Günes, H. Neugebauer, and N. S. Sariciftci, Chem. Rev. 107, 1324 (2007).

[6] U.E. Steiner and T. Ulrich, Chem. Rev. 89, 51 (1989).

[7] S. Nagakura, H. Hayashi, and T. Azumi Edited, Dynamic Spin Chemistry (Kodansha/Wiley, Japan/USA, 1998).

[8] Y. Tanimoto and Y. Fujiwara, in Handbook of Photochemistry and Photobiology: Inorganic Photochemistry, edited by H. S. Nalwa (American Scientific Publishers, 2003), Vol. 1, pp. 413-446.

[9] H. Yonemura, H. Tokudome, and S. Yamada, Chem. Phys. Lett. 346, 361 (2001).

[10] H. Yonemura, M. Noda, K. Hayashi, H. Tokudome, S. Moribe, and S. Yamada, Mol. Phys. 100, 1395 (2002).

[11] H. Yonemura, S. Moribe, K. Hayashi, M. Noda, H. Tokudome, S. Yamada, and N. Nakamura, Appl. Magn. Reson. 23, 289 (2003).

[12] S. Moribe, H. Yonemura, and S. Yamada, Chem. Phys. Lett. 398, 427 (2004).

[13] S. Moribe, H. Yonemura, and S. Yamada, C. R. Chim. 9, 247 (2006).

[14] S. Moribe, H. Yonemura, and S. Yamada, Chem. Phys. 334, 242 (2007).

[15] H. Yonemura, H. Nobukuni, S. Moribe, S.Yamada, Y. Fujiwara, and Y. Tanimoto, Chem. Phys. Lett. 358, 417 (2004).

[16] H. Yonemura, S. Harada, S. Moribe, S.Yamada, H. Nakamura, Y. Fujiwara, and Y. Tanimoto, Mol. Phys. 104, 1559 (2006). 
[17] H. Yonemura, Y. Motoda, and S.Yamada, Appl. Magn. Reson. 38, in press (2010).

[18] Y. Fujiwara, T. Aoki, K. Yoda, H. Cao, M. Mukai, T. Haino, Y. Fukazawa, Y. Tanimoto, H. Yonemura, T. Matsuo, and M. Okazaki, Chem. Phys. Lett. 259, 361 (1996).

[19] L. Pasimeni, M. Ruzzia, M. Prato, T.D. Ros, G. Barbarella, and M. Zambianchi, Chem. Phys. 263, 83 (2001).

[20] Y. Fujiwara, J. Hamada, T. Aoki, T. Shimizu, Y. Tanimoto, H. Yonemura, S. Yamada, T. Ujiie, and H. Nakamura, Mol. Phys. 100, 1405 (2002).

[21] Y. Tanimoto, N. Samejima, T. Tamura, M. Hayashi, A. Kita, and M. Itoh, Chem. Phys. Lett. 188, 446 (1992).

[22] N. I. Avdievich and M. D. E. Forbes, J. Phys. Chem. 99, 9660 (1995).

[23] H. Yonemura, S. Moribe, H. Nobukuni, M. Noda, K. Hayashi, S. Yamada, H. Nakamura, Y. Araki, and O. Ito, Fullerenes 13, 175 (2003).

[24] D. Clarke, B.C.Gilbert, P. Hanson, and C. M. Kirk, J. Chem. Soc. Perkin Trans. 2, 1103 (1978).

[25] T. Kato, T, Kodama, and T. Shida, Chem. Phys. Lett. 205, 405 (1993).

[26] L. Pasimeni, M. Ruzzia, M. Prato, T.D. Ros, G. Barbarella, and M. Zambianchi, Chem. Phys. 263, 83 (2001).

[27] G. L. Closs, M. D. E. Forbes, and J. R. Norris Jr, J. Phys. Chem. 91, 3592 (1987).

[28] C. D. Buckley, D. A. Hunter, P. J. Hore, and K. A. Mclauchlan, Chem. Phys. Lett. 135, 307 (1987).

[29] R. A. Marcus and N. Sutin, Biochim. Biophys. Acta 811, 265 (1985).

[30] R. M. Williams, J. M. Zwier, and J. W. Verhoeven, J. Am. Chem. Soc. 117, 4093 (1995). 
[31] T. D. M. Bell, , K. P. Ghiggino, K. A. Jolliffe, M. G. Ranasinghe, S. J. Langford, M. J. Shephard and M. N. Paddon-Row, J. Phys. Chem. A 106, 10079 (2002).

[32] S. Sekiguchi, Y. Kobori, K. Akiyama, and S. Tero-Kubota, J. Am. Chem. Soc. 120, 1325 (1998).

[33] Y. Kobori, S. Sekiguchi, K. Akiyama and S. Tero-Kubota, J. Phys. Chem. A 103, 5416 (1999). 


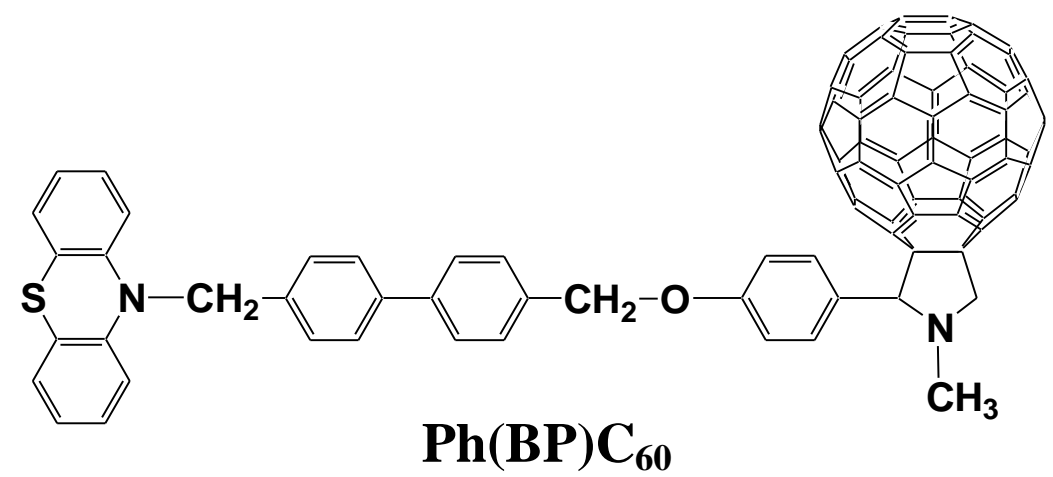

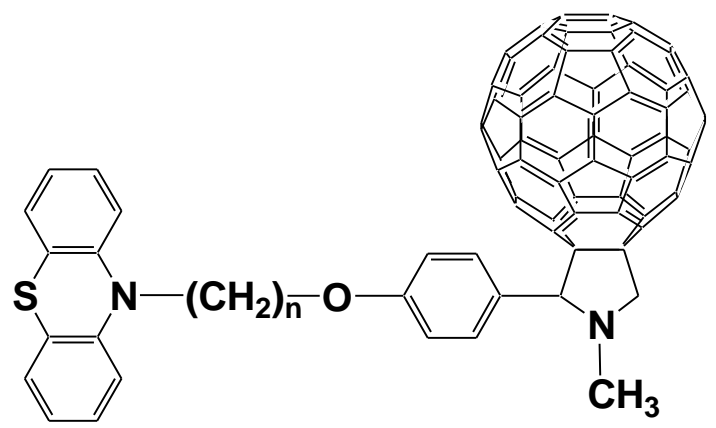

$\operatorname{Ph}(n) C_{60}(n=4,6,8,10,12)$

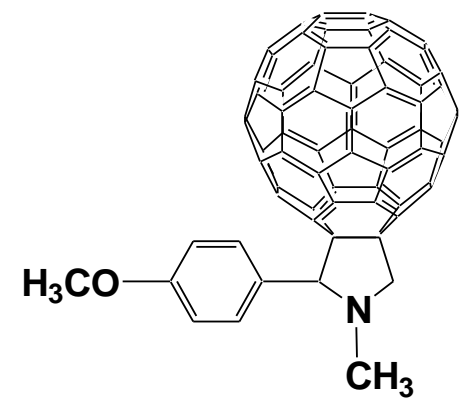

$\mathrm{C}_{60}$ ref

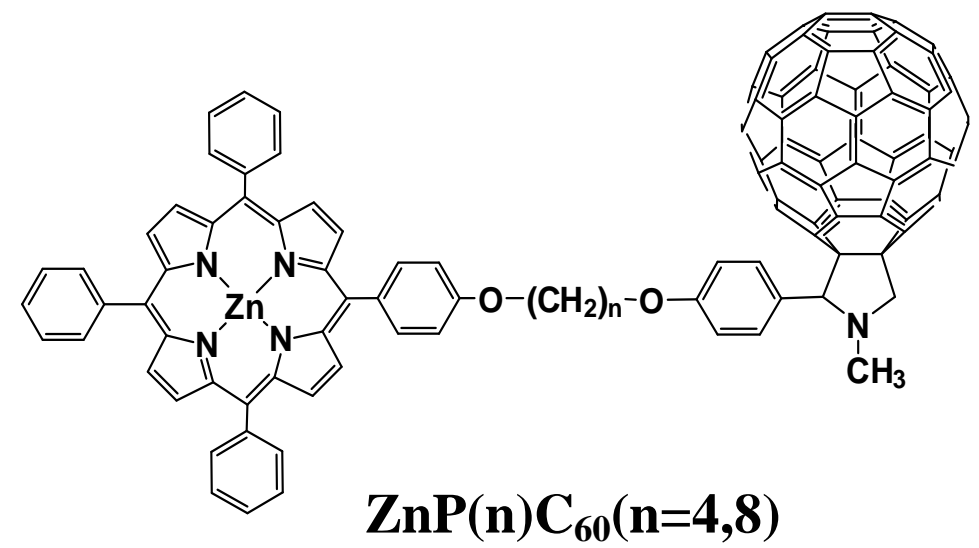

Scheme 1. Molecular structures of $\mathrm{Ph}-\mathrm{C}_{60}$ linked compounds with a biphenyl group and methylene groups $\left(\mathbf{P h}(\mathbf{B P}) \mathbf{C}_{60}\right.$ and $\left.\mathbf{P h}(\mathbf{n}) \mathbf{C}_{60}(\mathbf{n}=\mathbf{4}, \mathbf{6}, \mathbf{8}, \mathbf{1 0}, \mathbf{1 2})\right)$ and $\mathrm{ZnP}-\mathrm{C}_{60}$ linked compounds with methylene groups $\left(\operatorname{ZnP}(\mathbf{n}) \mathbf{C}_{\mathbf{6 0}}(\mathbf{n}=\mathbf{4 ,}, \mathbf{8})\right)$ and a reference $C_{60}$ compound $\left(\mathbf{C}_{60} \mathbf{r e f}\right)$. 


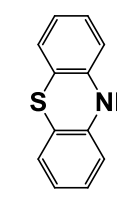<smiles>BrCc1ccc(-c2ccc(CBr)cc2)cc1</smiles>

1
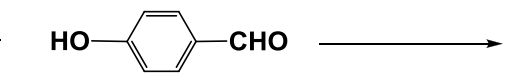

$2+\mathrm{C}_{60}+\mathrm{CH}_{3} \mathrm{NHCH}_{2} \mathrm{COOH}$
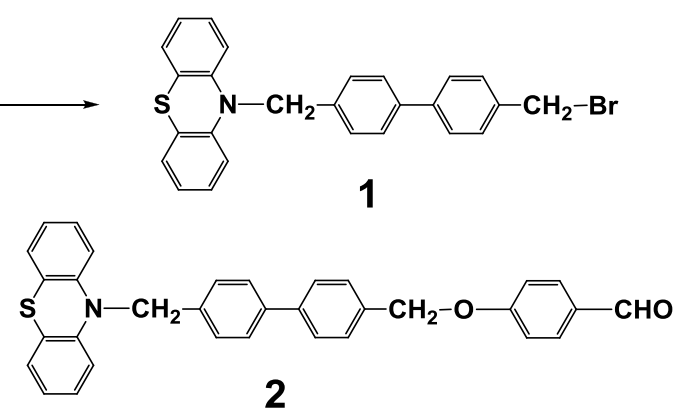

2

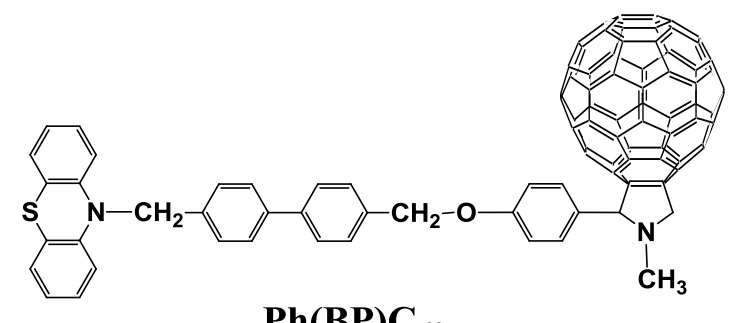

$\operatorname{Ph}\left(\mathrm{BP} \mathbf{C}_{60}\right.$

Scheme 2. Synthesis of a $\mathrm{Ph}-\mathrm{C}_{60}$ linked compound with a biphenyl group as a semirigid spacer $\left(\mathbf{P h}(\mathbf{B P}) \mathbf{C}_{60}\right)$. 


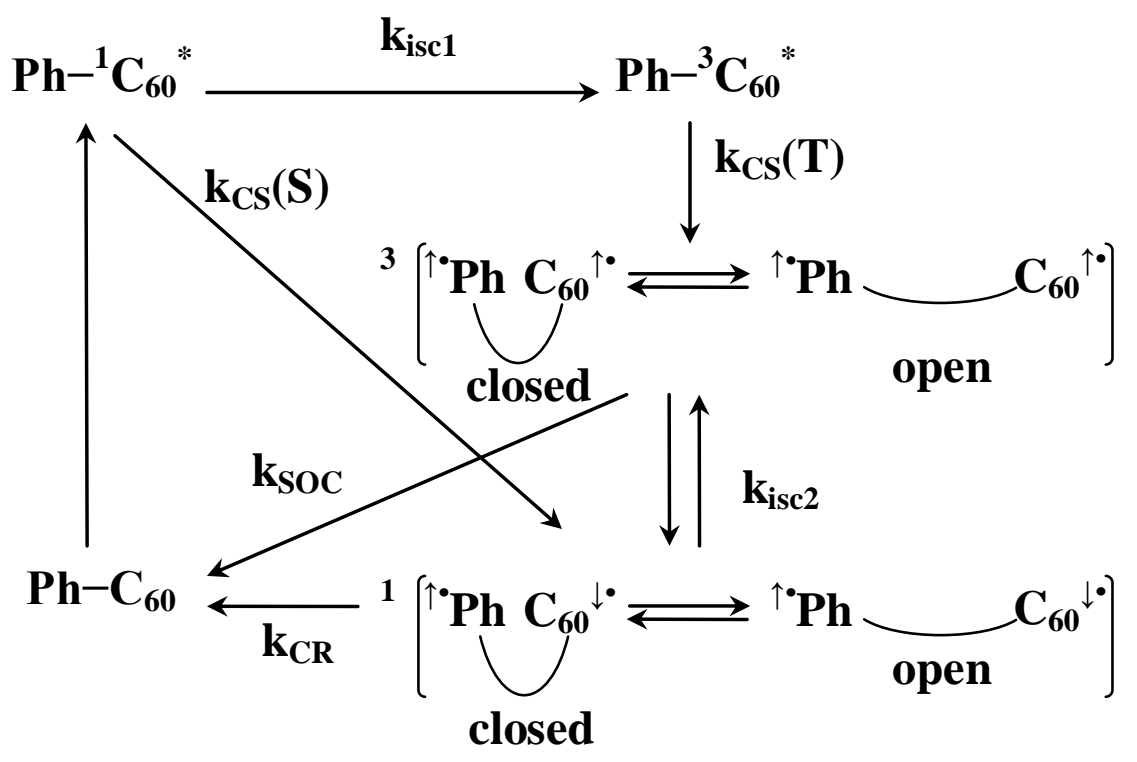

Scheme 3. Reaction scheme of $\mathbf{P h}(\mathbf{B P}) \mathbf{C}_{60}$ and $\mathbf{P h}(\mathbf{n}) \mathbf{C}_{60}(\mathbf{n}=4-12)$ in benzonitrile. 


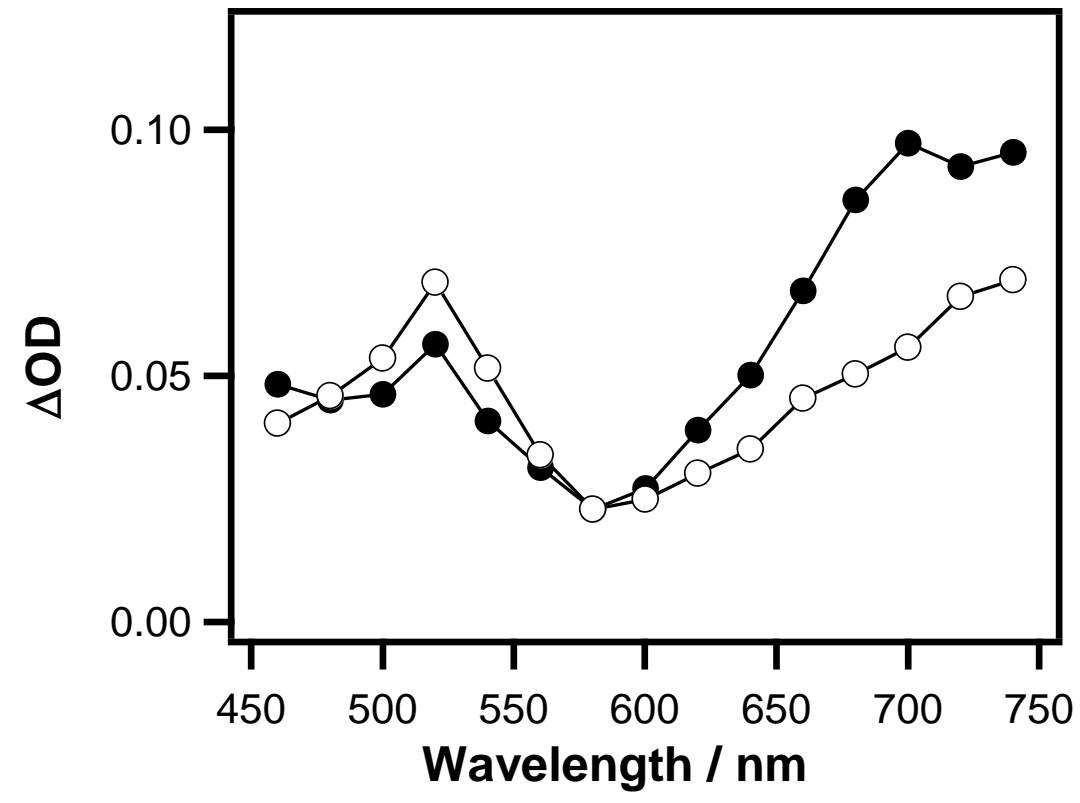

Figure 1. Transient absorption spectra of $\mathbf{P h}(\mathbf{B P}) \mathbf{C}_{\mathbf{6 0}}\left(1.0 \times 10^{-4} \mathrm{~mol} \mathrm{dm}^{-3}\right)$ at 0.03 $\mu \mathrm{s}(\circ)$ and $0.06 \mu \mathrm{s}(\bullet)$ in benzonitrile after laser excitation at $283 \mathrm{~K}$. 

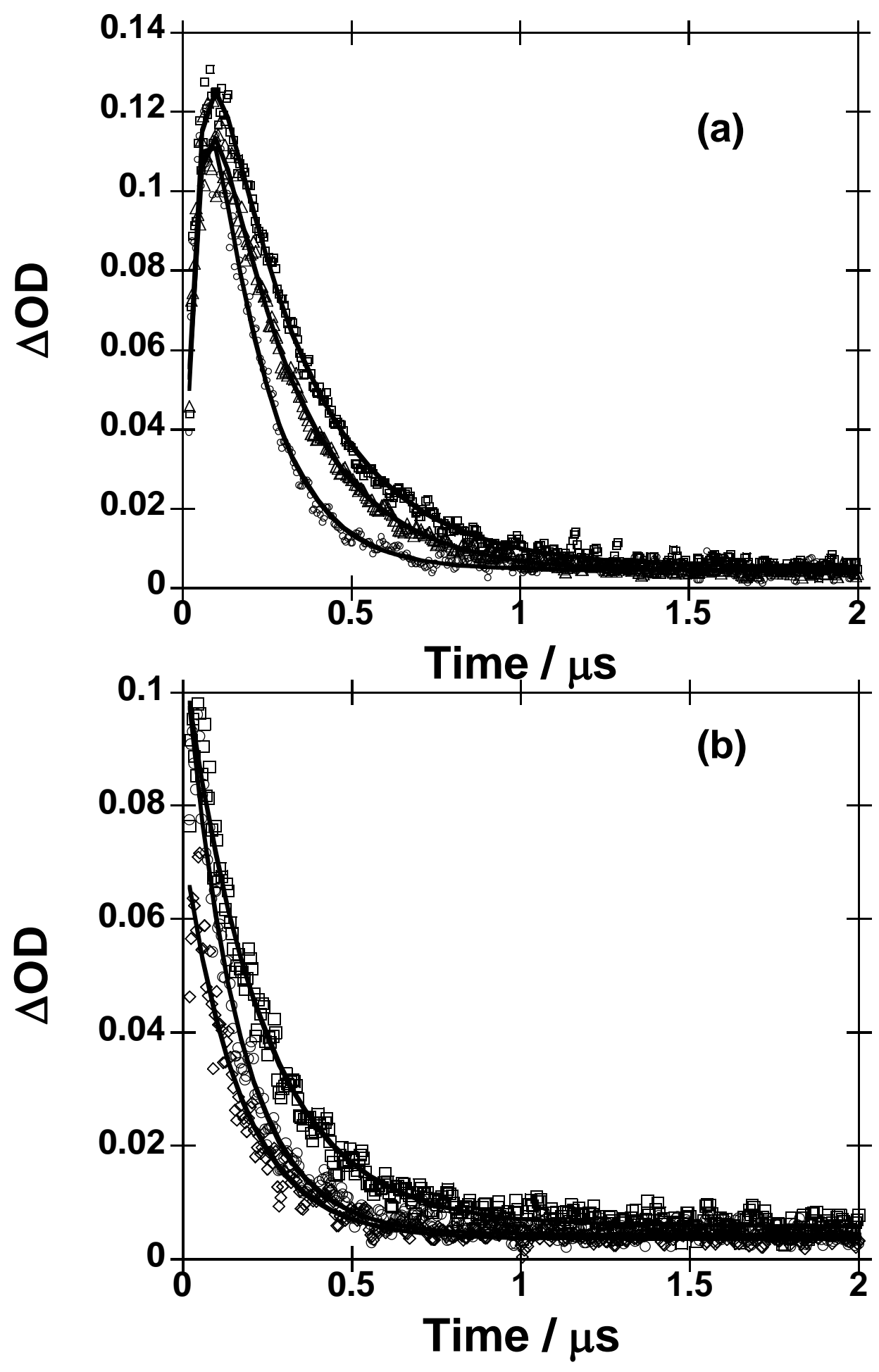

Figure 2. Decay profiles of transient absorption of $\mathbf{P h}(\mathbf{B P}) \mathbf{C}_{60}$ at $520 \mathrm{~nm}$ in benzonitrile at $0(\circ), 0.1(\square)$ and $1.0(\diamond) \mathrm{T}$ at (a) $283 \mathrm{~K}$ and (b) $343 \mathrm{~K}$. Solid lines correspond to fitting curves. 


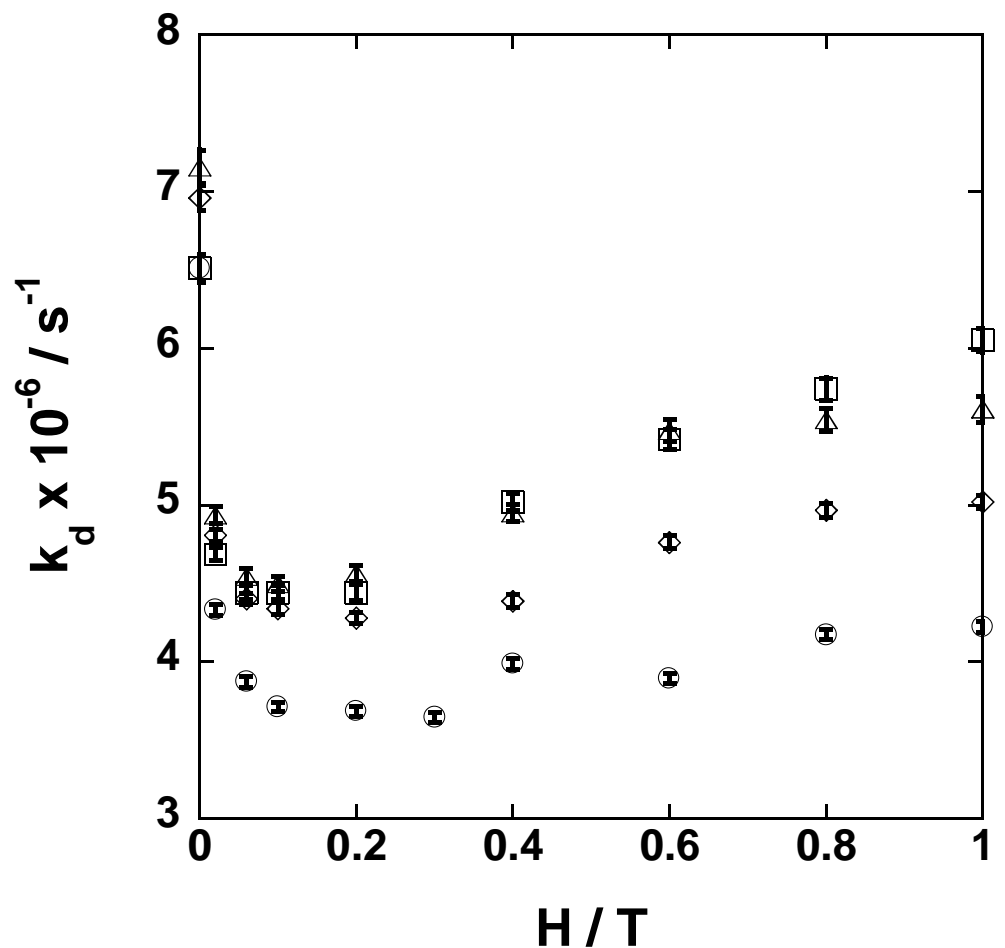

Figure 3. The temperature dependence of the MFEs on the decay rate constants $\left(k_{d}\right)$ for the biradical as evaluated from the transient absorption at $520 \mathrm{~nm}$ upon laser excitation of $\mathbf{P h}(\mathbf{B P}) \mathbf{C}_{60}$ in benzonitrile at $283(\circ), 303(\diamond), 323(\Delta)$ and $343(\square) \mathrm{K}$. Error bars correspond to standard deviation in non-linear least-squares method for Equation (1). 

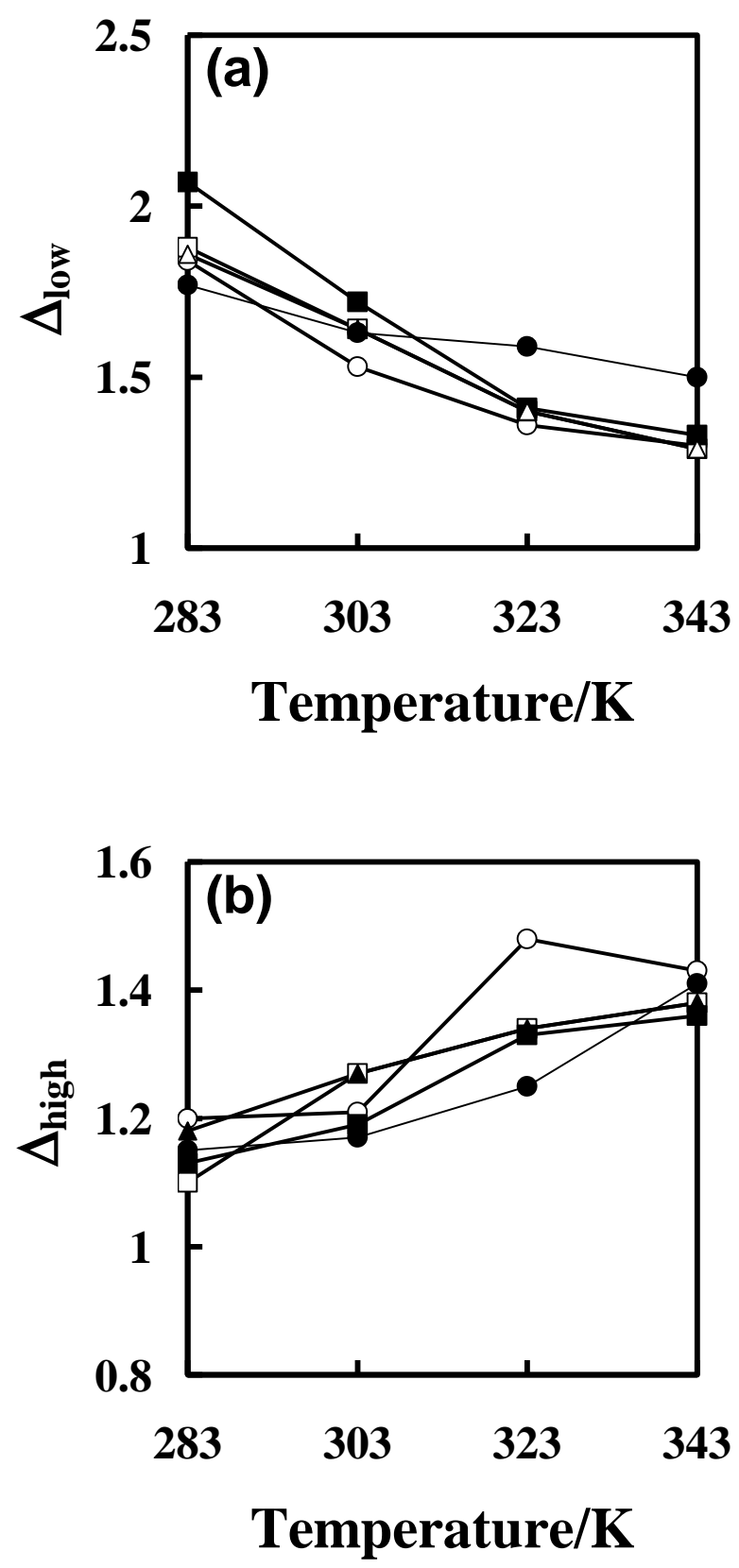

Figure 4. The temperature dependence on the $\Delta_{\text {low }^{-}}$(a) and $\Delta_{\text {high }^{-v a l u e s}}$ (b) in $\operatorname{Ph}(\mathrm{BP}) \mathbf{C}_{60}$ and $\mathbf{P h}(\mathbf{n}) \mathbf{C}_{60}(\mathbf{n}=\mathbf{6 - 1 2})[14]: \mathbf{P h}(\mathbf{B P}) \mathbf{C}_{60}(\bullet), \operatorname{Ph}(6) \mathbf{C}_{60}(0), \operatorname{Ph}(8) \mathbf{C}_{60}$ $(\square), \operatorname{Ph}(10) \mathbf{C}_{60}(\square)$ and $\operatorname{Ph}(12) \mathbf{C}_{60}(\Delta)$. 


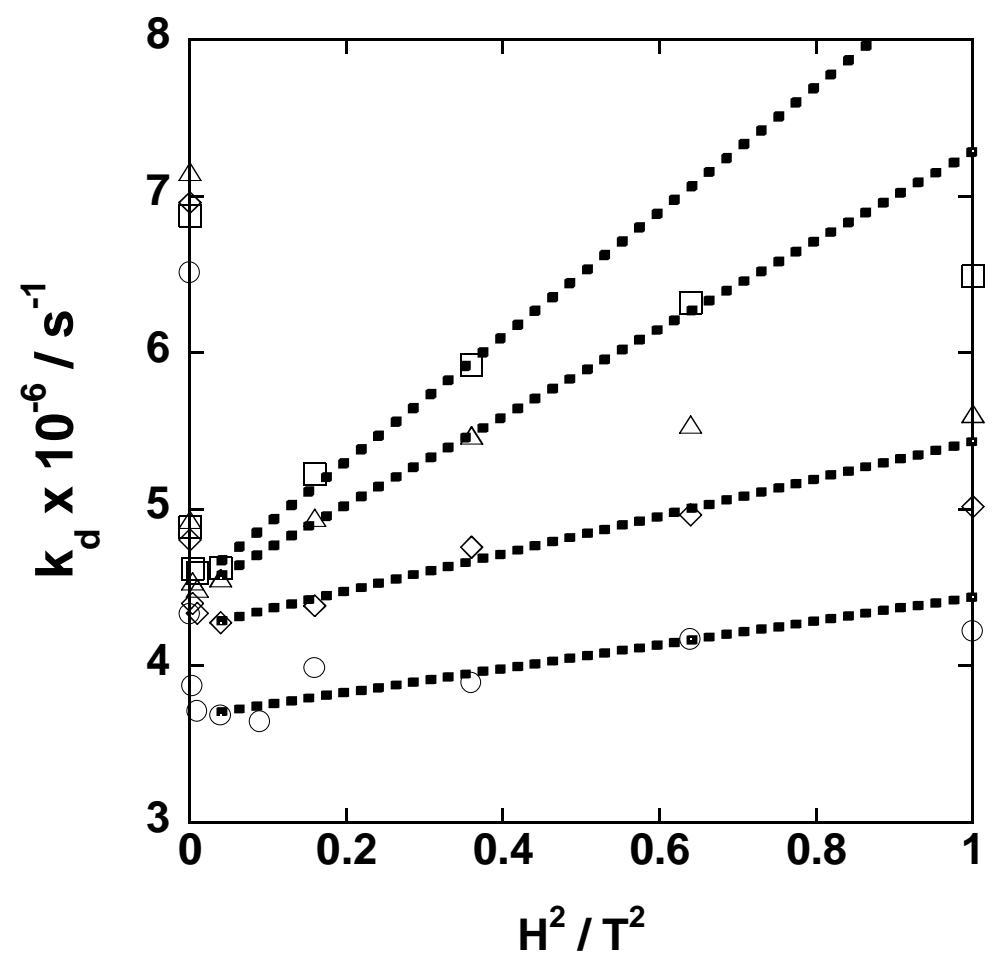

Figure 5. Plots of the decay rate constants $\left(\mathrm{k}_{\mathrm{d}}\right)$ versus $\mathrm{H}^{2}$ in $\mathbf{P h}(\mathbf{B P}) \mathbf{C}_{\mathbf{6 0}}$ at $283(\mathrm{\circ}), 303$ $(\diamond), 323(\Delta)$ and $343(\square) \mathrm{K}$. R-values in linear least-squares method for Equation (2) $\left(283 \mathrm{~K}(\mathrm{R}=0.86)\right.$ and $303 \mathrm{~K}(\mathrm{R}=0.98)$ in magnetic field region $\left(0.04-0.64 \mathrm{~T}^{2}\right), 323 \mathrm{~K}$ $(\mathrm{R}=0.99)$ and $343 \mathrm{~K}(\mathrm{R}=0.99)$ in magnetic field region $\left.\left(0.01-0.36 \mathrm{~T}^{2}\right)\right)$. 

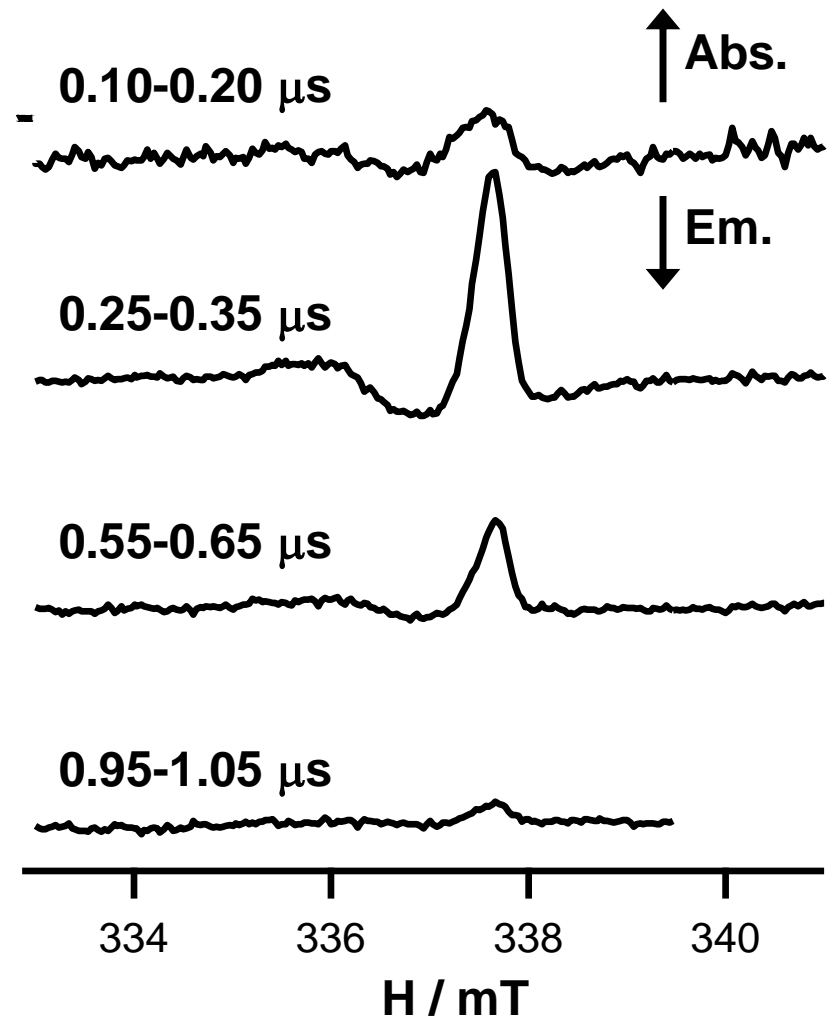

Figure 6. Time-resolved EPR spectra of $\mathbf{P h}(\mathbf{B P}) \mathbf{C}_{60}$ in benzonitrile at room temperature and several delay times after laser excitation. 
Table 1. Relative fluorescence intensities of $\mathbf{P h}(\mathbf{n}) \mathbf{C}_{\mathbf{6 0}}(\mathbf{n}=\mathbf{4 , 1 0 , B P})$ in benzonitrile at 283K.

\begin{tabular}{cc}
\hline compounds & $\mathrm{I}_{\mathbf{0}}{ }^{\mathrm{a}}$ \\
\hline $\mathrm{Ph}(4) \mathrm{C}_{60}$ & $\mathbf{0 . 6 0}$ \\
$\mathrm{Ph}(\mathbf{1 0}) \mathrm{C}_{60}$ & 0.79 \\
$\operatorname{Ph}(\mathrm{BP}) \mathrm{C}_{60}$ & 0.89 \\
\hline
\end{tabular}

${ }^{\mathrm{a}} \mathrm{I}_{0}$ : fluorescence intensity of $\mathbf{C}_{\mathbf{6 0}} \mathbf{r e f}$. 